\title{
OPTIMIZATION MODEL FOR REGIONAL DEVELOPMENT UNITS IN EGYPT
}

\author{
Shehab Mahmoud Mohamed, Mohammed Shukry, Reda Ibrahim Abdel Hamid, \\ Bakr Hashem Bayoumy, and Hassanein Mohammed Abu Zaid \\ Department of Physical Planning - Faculty of Engineering - Al-Azhar University \\ eng.shopary86@gmail.com,redafeteh@gmail.com,drbakr@gmail.com, \\ Scale_2004@yahoo.com
}

\begin{abstract}
:
Studies and research at any regional level differed for development in Egypt due to differences and gaps in development and their concentration in large urban centers. Despite the existence of development plans prepared by the General Authority for Urban Planning at the national level and the planning regions and the preparation of strategic plans for some Egyptian governorates and on the level of Cities and territories. Any of these levels is suitable for a real development boom that shows results on the ground. This study also sought to show the development problems in Egypt and how to reach the governorate as an administrative unit, DONC were urban or rural are best suited for regional development, as they constitute increasingly important units for development policy making. They play a role in creating a regional balance and a fair distribution of national resources and capacities. They represent the cornerstone for the launching of development, as they have the necessary resources and resources to help develop them. The study recommended some recommendations: The necessity of activating decentralization of development and introducing the system of governorates as regional development units, while giving them a role in activating and implementing developmental trends and meeting their requirements, which help them to support and attract activities and investments in different development sectors.
\end{abstract}

Keywords: Development, Regional Development, Region, Governorate, Effective Decentralization, Strategic Management.

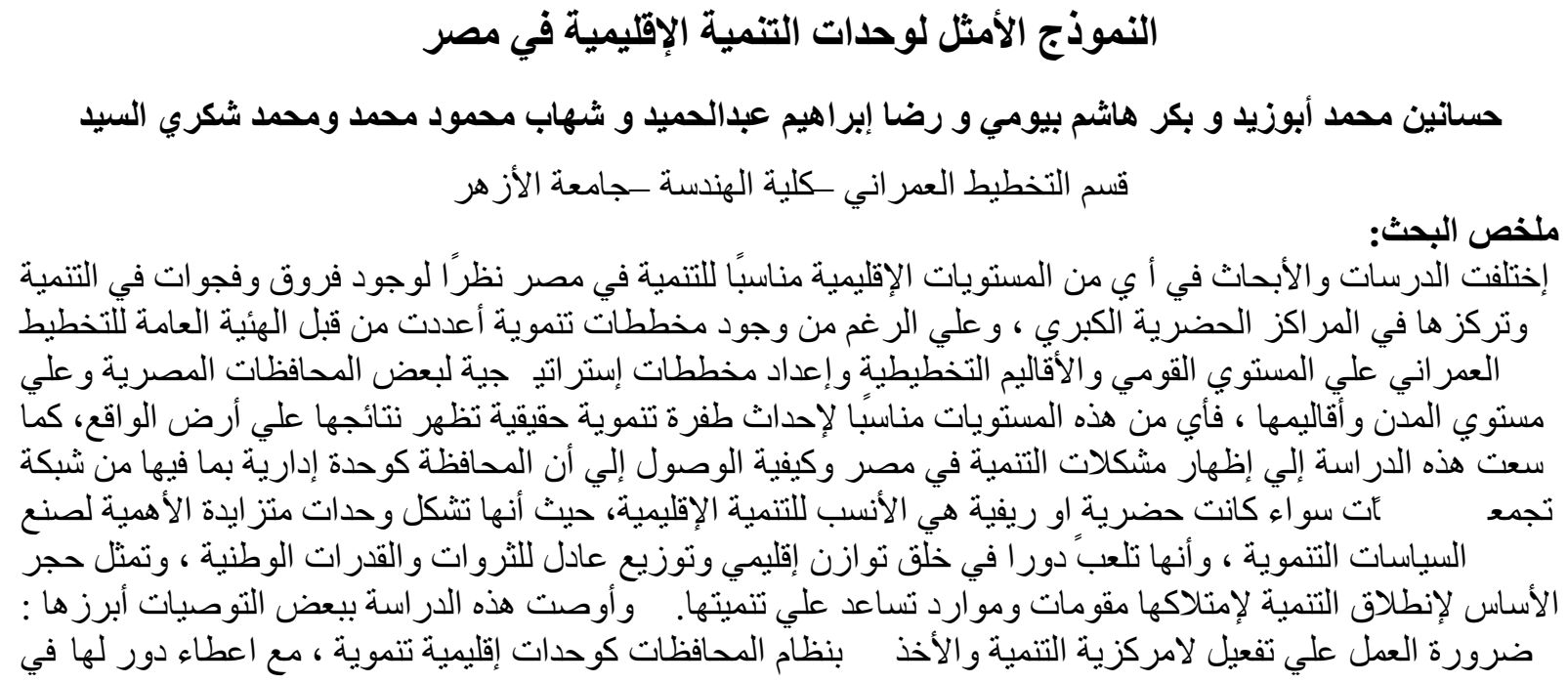


تفعيل وتنفيذ التوجهات الإنمائية وتلبية متطلباتها ، و التي تساعدها علي دعم وجذب الأنشطة والإستثمار ات بقطاعات التتمية المختلفة الكلمات الإفتتاحية : التتمية، التتمية الإقليمية ، الإقليم، المحافظة ، اللامركزية الفعالة ، الإدارة الإستراتيجية.

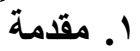

أصبحت قضية البحث عن بديل أو أكثر لنماذج التتمية الإقليمية أحد المتطلبات الحيوية والإستر اتيجية و التي تمثل نقطة الإنطلاق نحو تحقيق

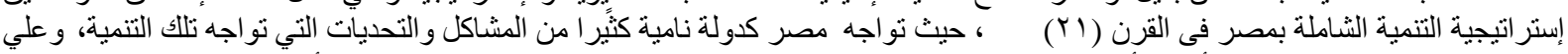

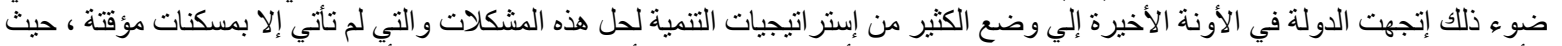

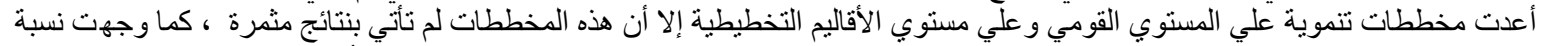

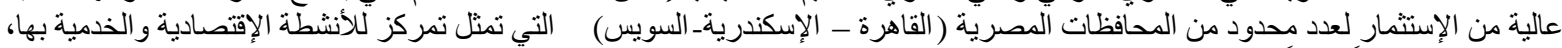

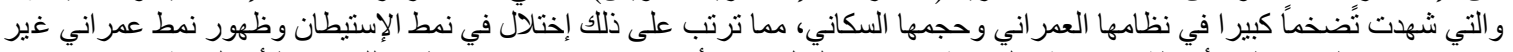

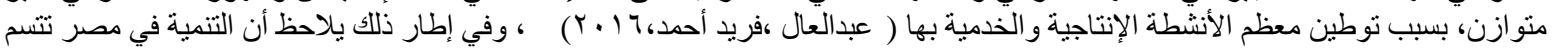

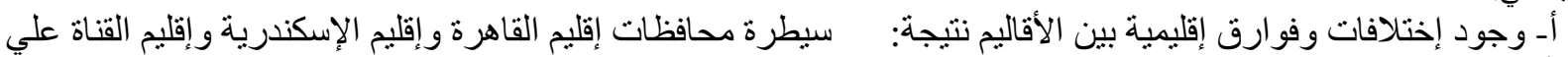

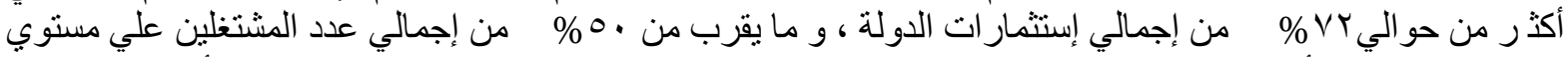

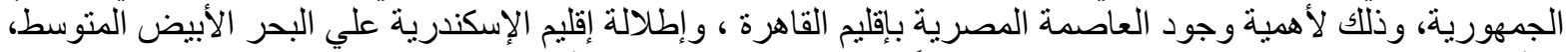

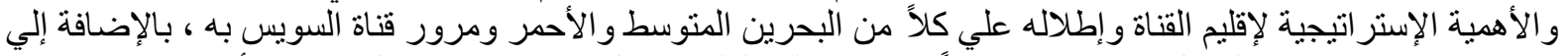

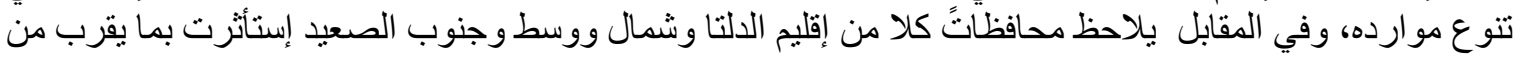

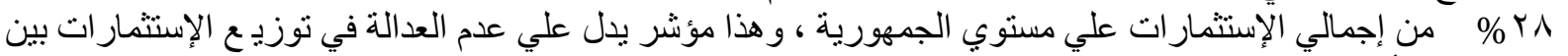

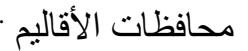

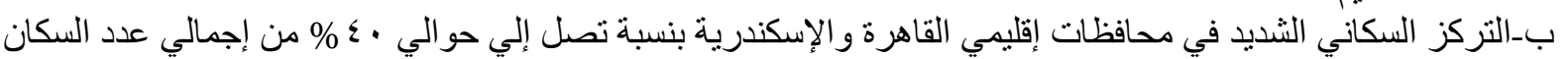

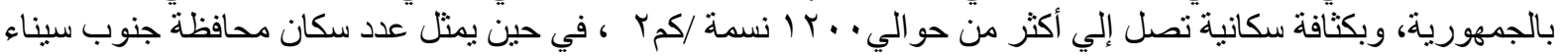
حوالي r · •\% من إجمالي سكان الجمهورية.

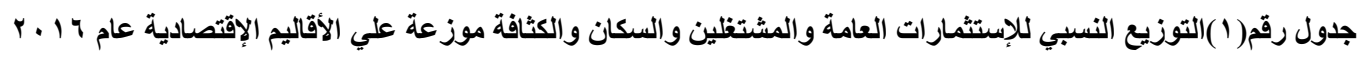

\begin{tabular}{|c|c|c|c|c|c|c|}
\hline 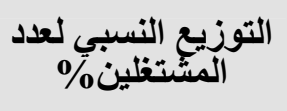 & للإستثنيعِ النسبي & اللتكانيع لاجيمائي & 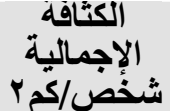 & المساحة بـ & السكاند & الإقليم \\
\hline$\% Y \leq . Y \leq$ & \% Tr.я. & $\% r \leqslant . \wedge i$ & ITIN.・V & $T V T \leqslant 1.9 Y$ & YY.10 & القاهرة \\
\hline$\% 1 \leq .11$ & $\% \backslash \pi . \leqslant \Lambda$ & $\% 1$ Y.OV & $r \leqslant 9.99$ & rTIVo.9 & 11.01 & الإسكندريـة \\
\hline$\% 11.17$ & $\%$ Y. $1 \leq$ & $\% 1 \cdot . \wedge 0$ & $1 Y \leqslant .0$ & $1.0 \wedge \wedge .9 \mathrm{~V}$ & 9.99 & القناة \\
\hline \%rr.r & $\% \wedge . \varepsilon r$ & $\%$ \% 1.71 & $171 \% . \mathrm{YV}$ & IYTOV.\&4 & $19.9 \mathrm{~V}$ & الالتا \\
\hline$\% \backslash r .1$ & $\% \leqslant .79$ & $\%$ \% . . & $179 . V \%$ & $991 Y 0$ & 11.10 & شُمال الصعيد \\
\hline$\% \varepsilon .0 \mathrm{~V}$ & $\% \varepsilon .0 Y$ & $\% 0.1 Y$ & $11 . V Y$ & $\varepsilon \cdot r \leqslant \Gamma$ & $\varepsilon . V I$ & وسط الصعيد \\
\hline$\%$ \%.$r$. & $\% 1 \cdot .17$ & $\% 1 Y . \cdot q$ & $\leqslant 1.9$ & KYVVOD. & $11.1 \pi$ & جنوب الصعيد \\
\hline$\% 1 \ldots$ & $\% 1 \ldots$ & $\% 1 \ldots$ & 1.9 .11 & $\Lambda \leqslant \Gamma \leqslant V \leqslant . V$ & 94.11 & الاجمالي \\
\hline
\end{tabular}

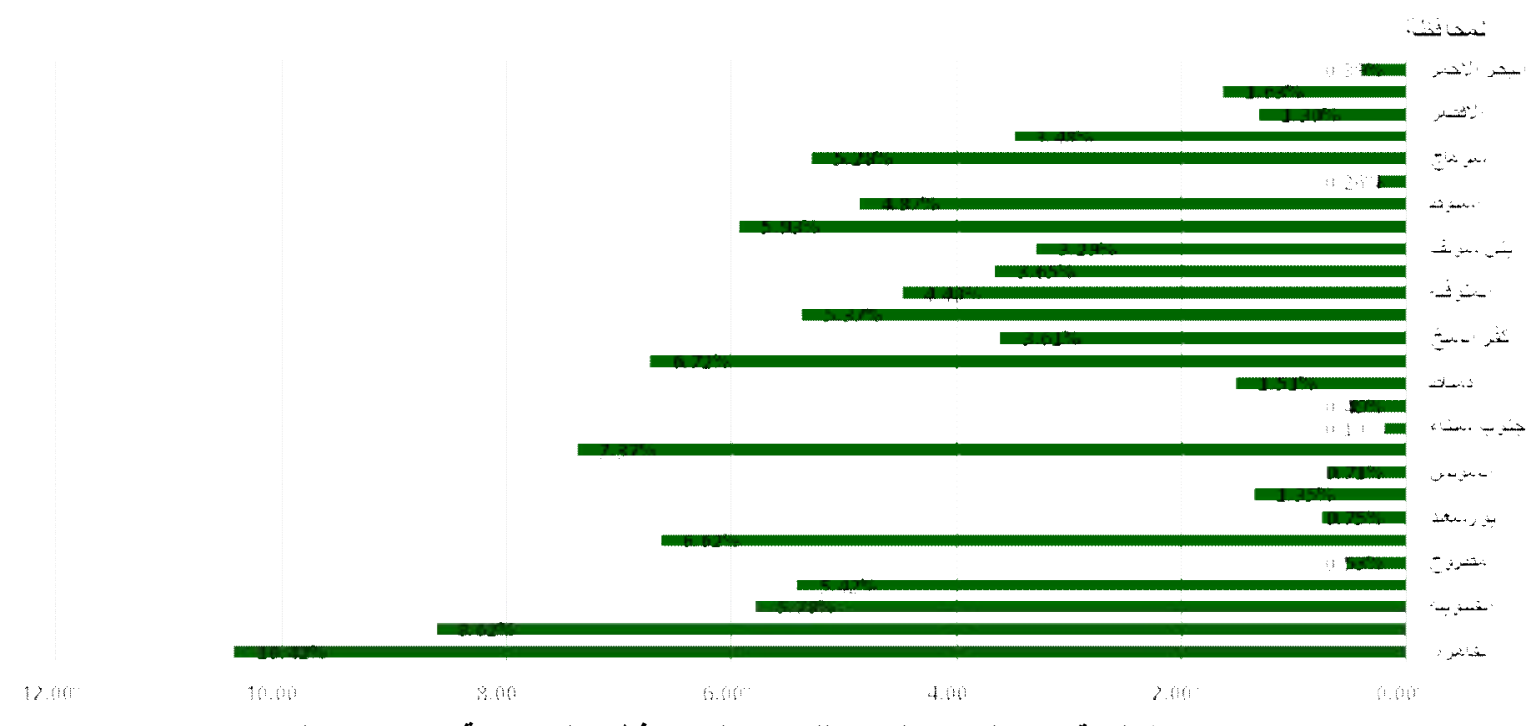

شكل رقم (1) التوزيع النسبي للسكان علي محافظات الجمهورية عام 14 ـ ب (الباحث) 


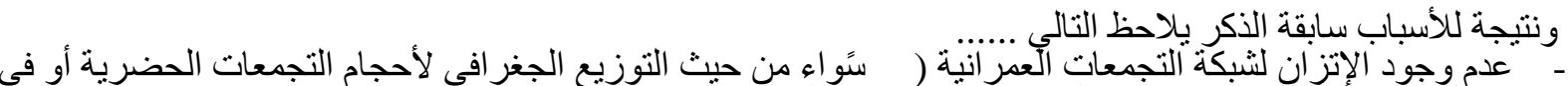

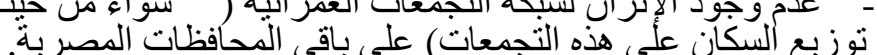

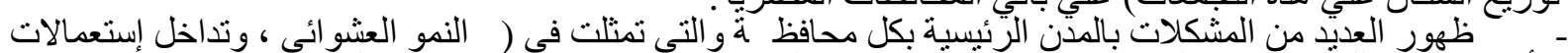

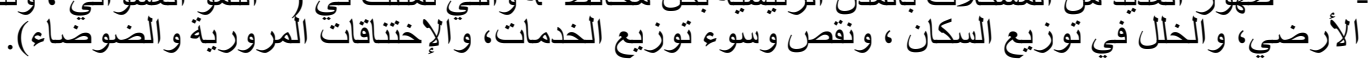

بَ بَ. المشكلة البحثية

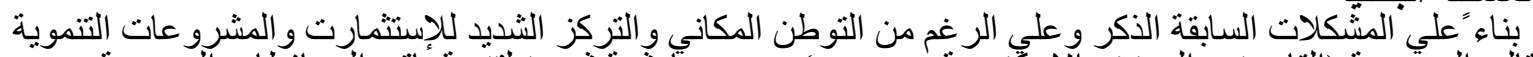

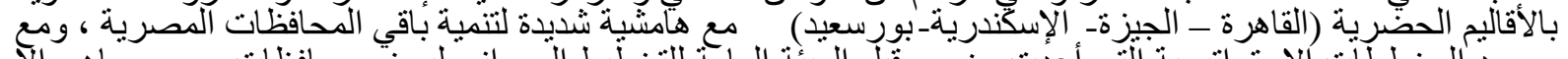

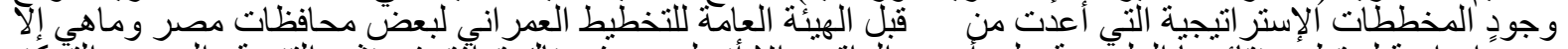

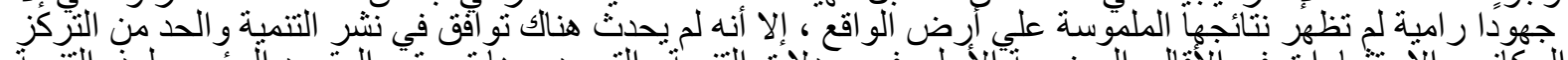

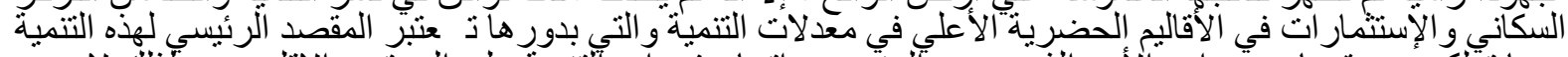

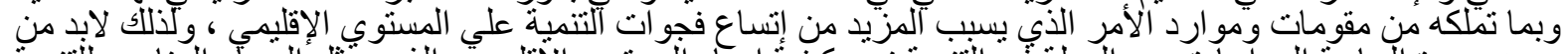

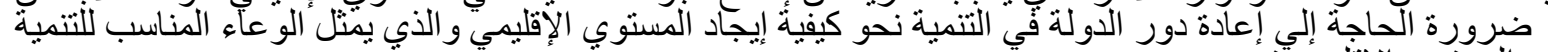

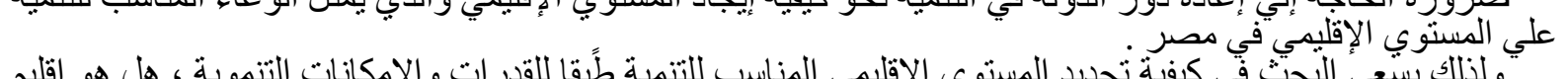

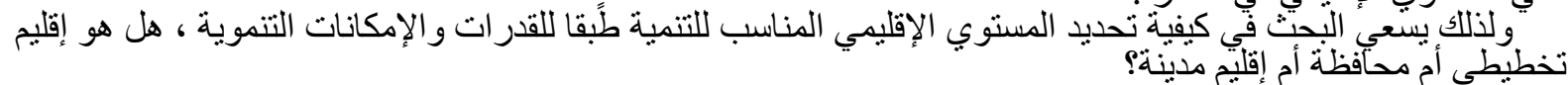

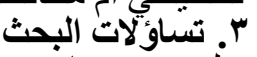

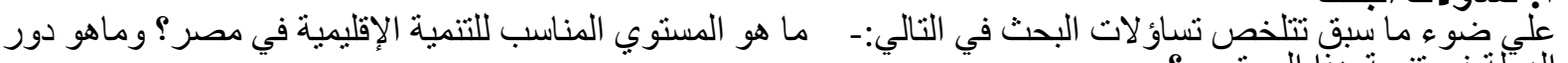

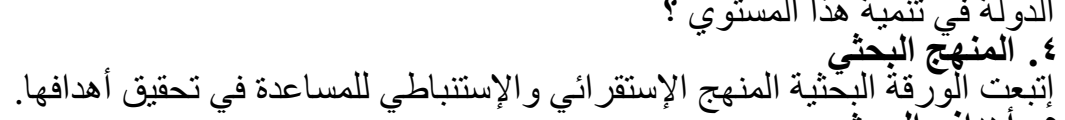

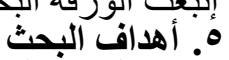

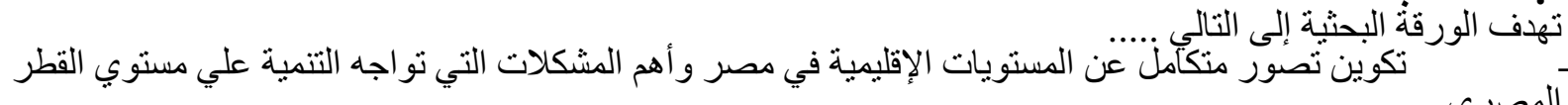
- المصرينياج ومعرفة أفضل مسنوي إقليمي مناسب للتنمية الإقليمية ، ليكون بمثابة المحرك و الدافع لعجلة التنمية الثناملة في

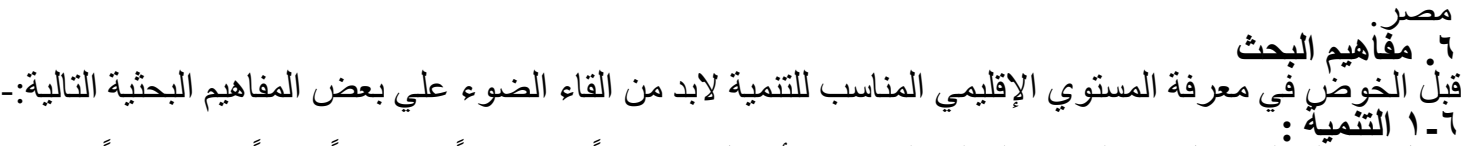

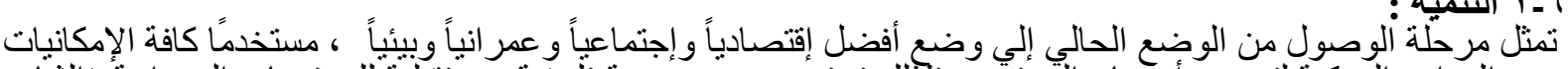

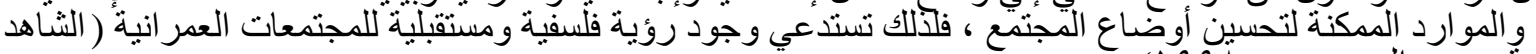

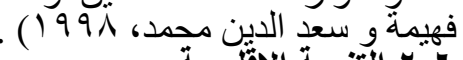

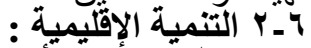

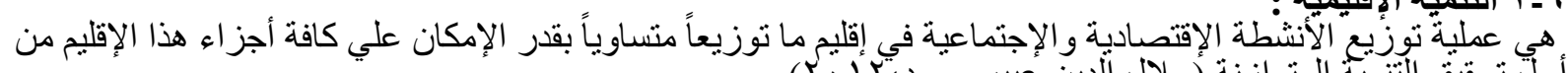

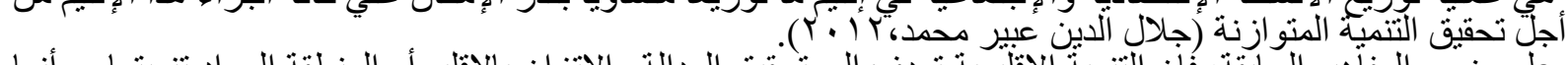

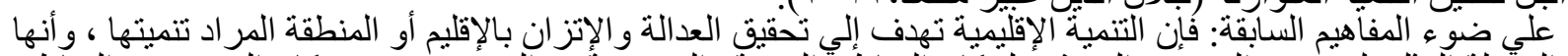

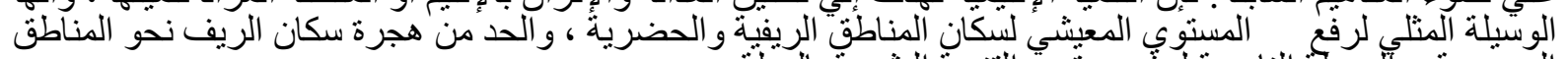

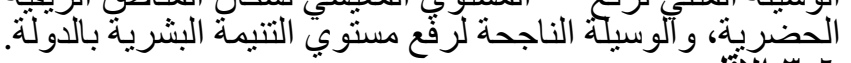

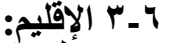

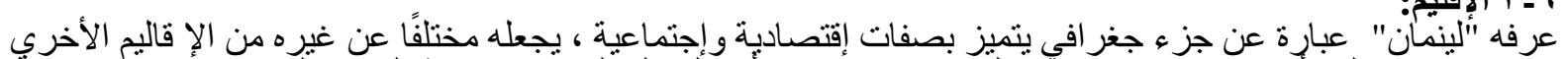

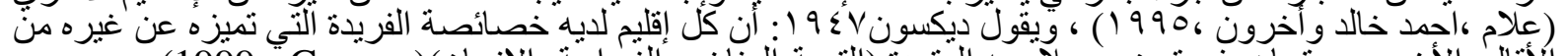

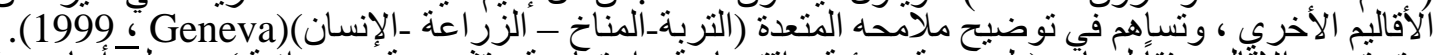

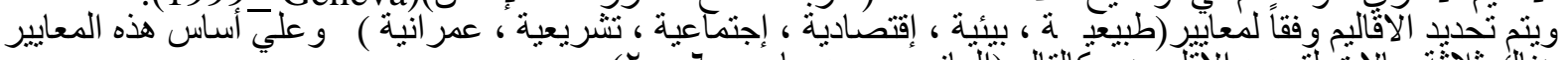

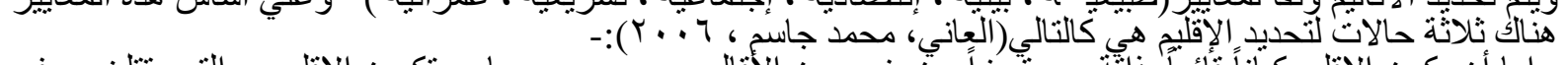

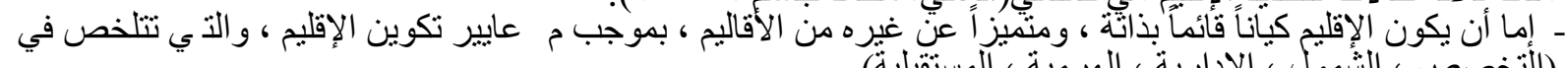

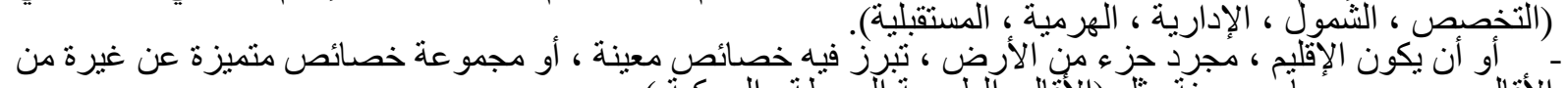

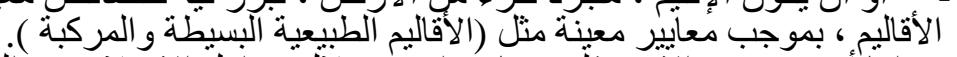

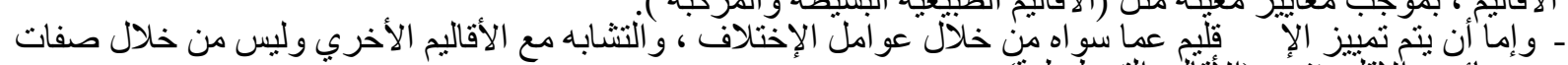

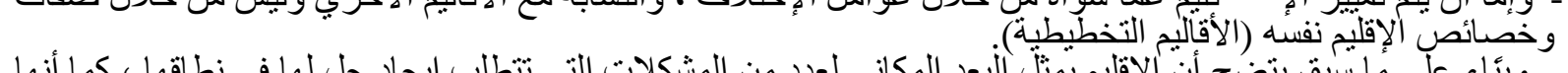

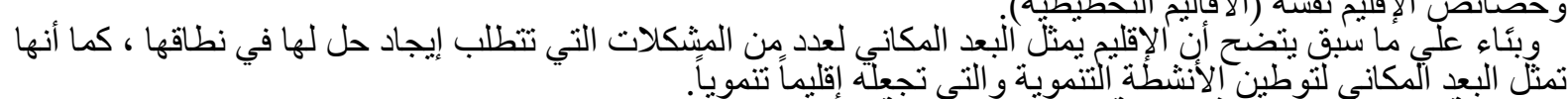

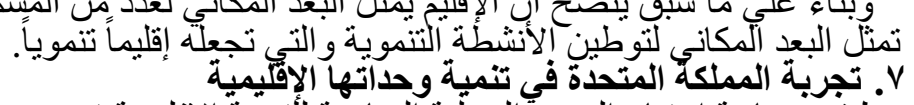

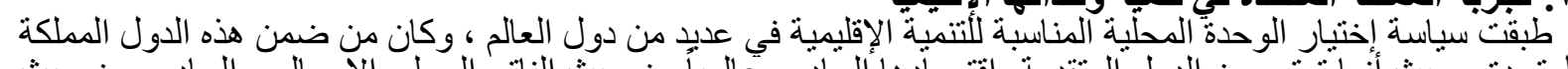

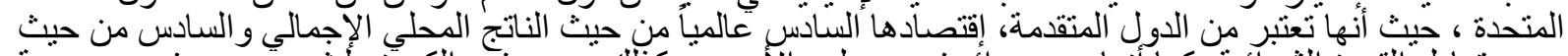

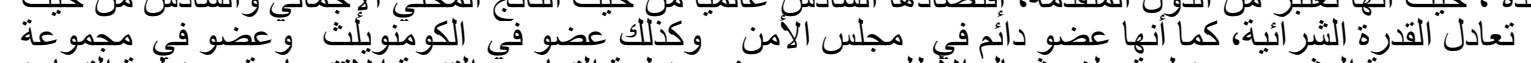

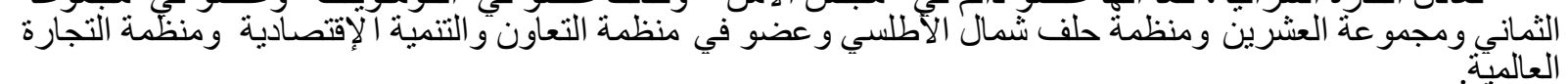

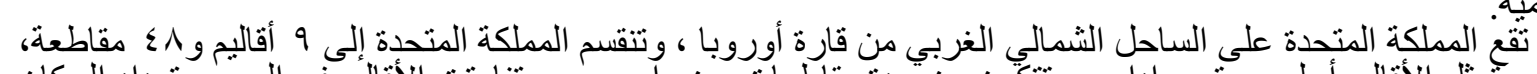

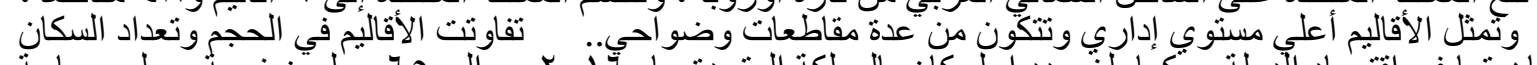

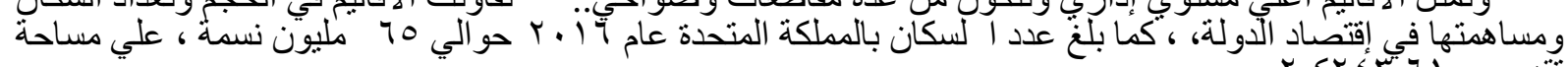

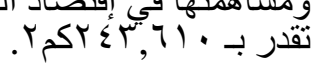




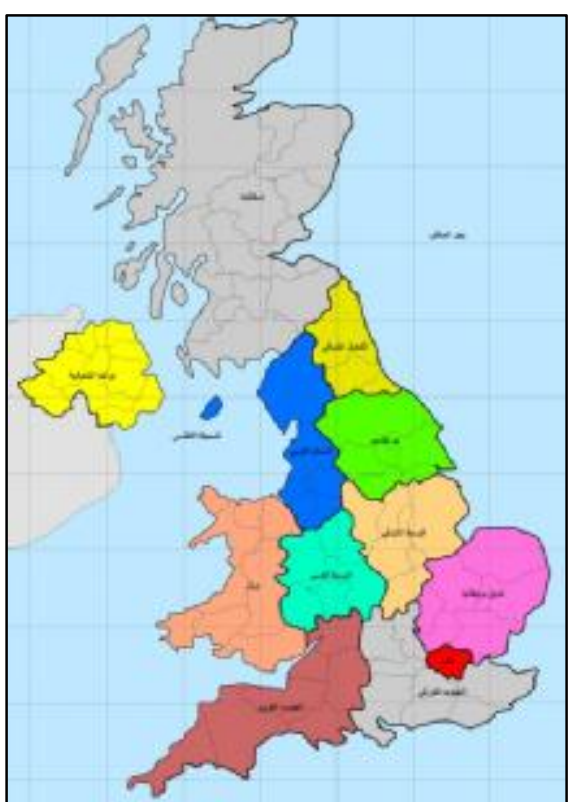

شكل رقم (ץ) تقسيم المملكة المتحدة إلى وحدات تنموية

كما واجهت المملكة المتحدة كثير اً من الـ مشكلات التنموية من أهمها المشكلات التالية:-(MICHAEL E PORTER).

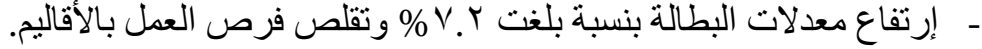

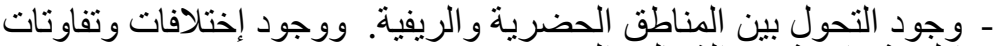
إقليمية و اسعة بين الثمال بين الثناطن والجنوب الحنرية.

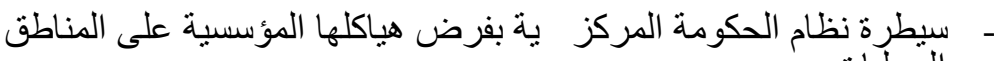

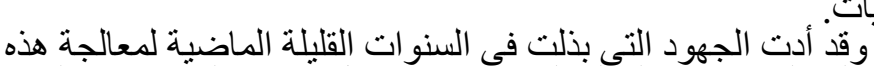

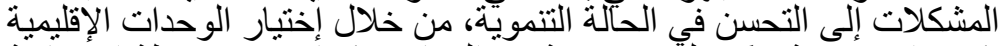

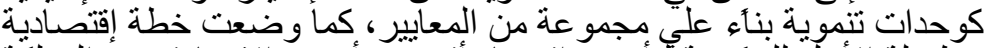

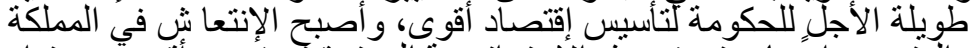

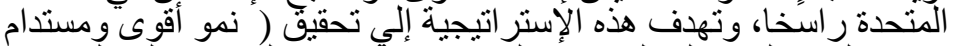

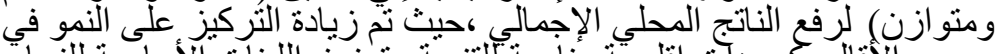

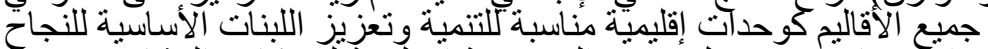

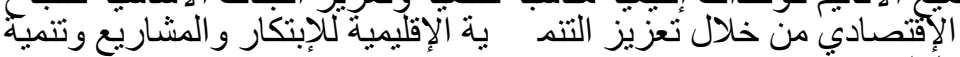

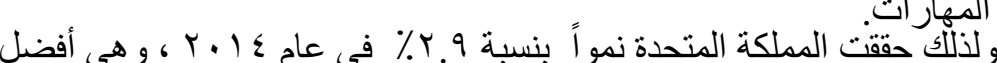

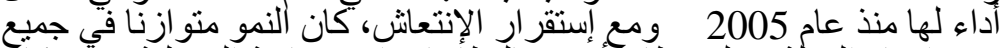

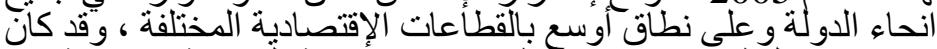

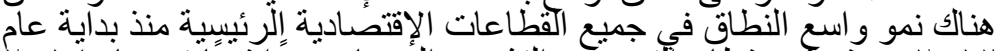

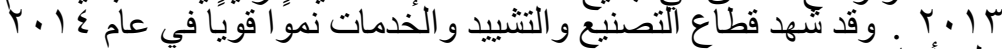
على أساس سنوي

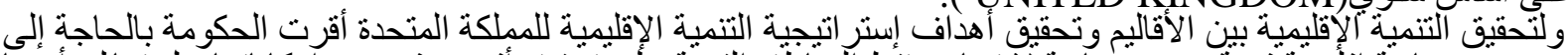

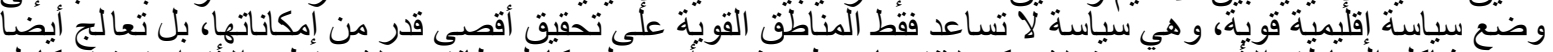

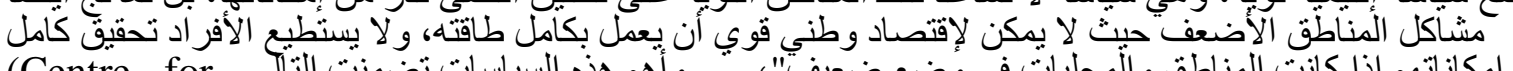

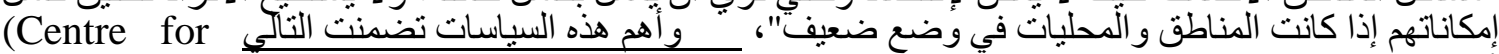
-:International)

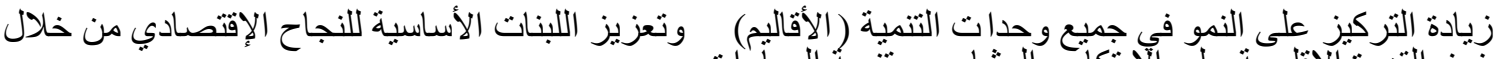

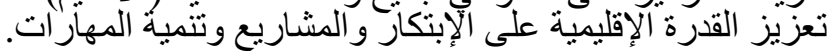

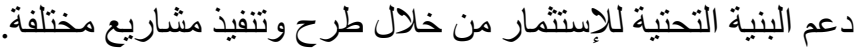
بناء سوق إسكان مستقرة من خلال إنشاء مناطق سكنية جديدة و عدد من التدابير الأخري. توفير التمويل للإستثمار الإنتاجي الذي يقدمه النظام النام المالي في المملكة المتحدة.

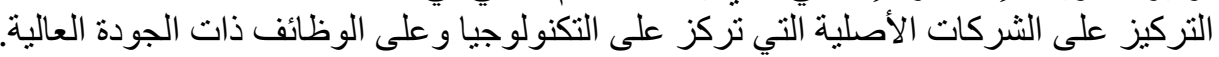

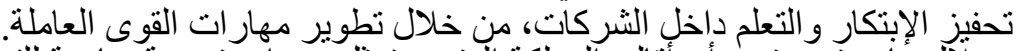

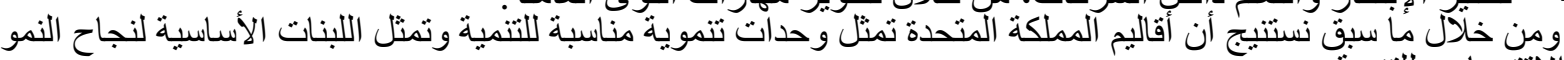
الإقتصنادي للتنمبة فئة

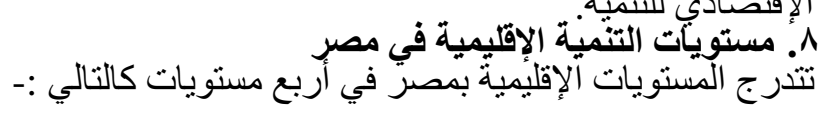

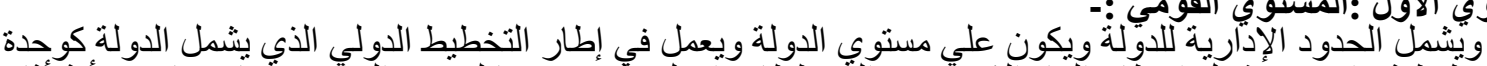

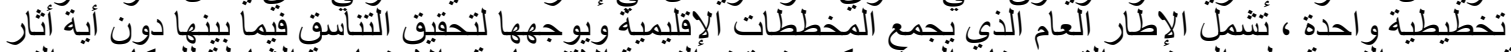

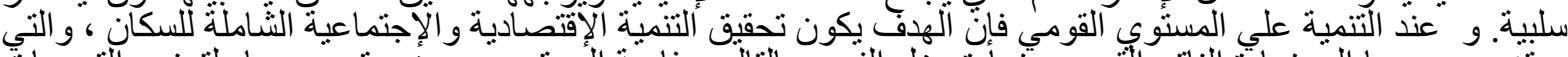

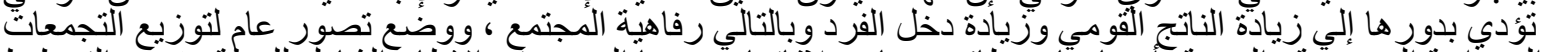

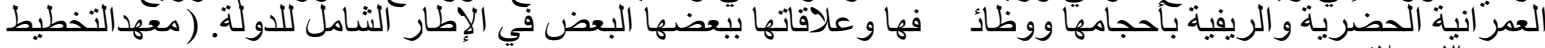

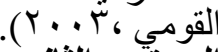

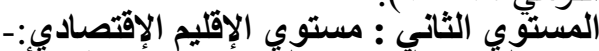

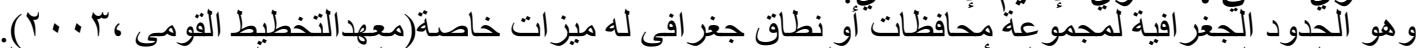

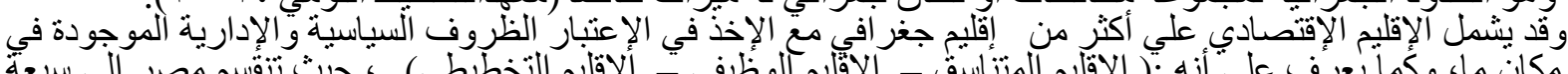

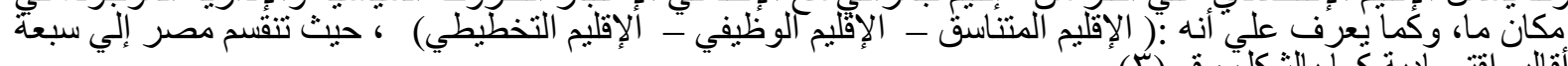

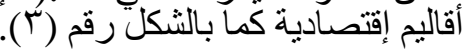

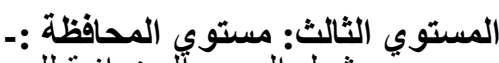

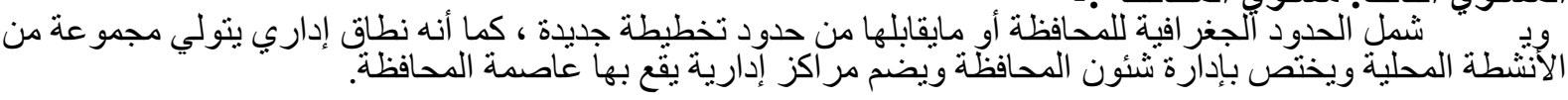




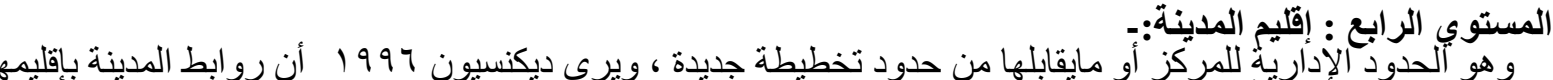

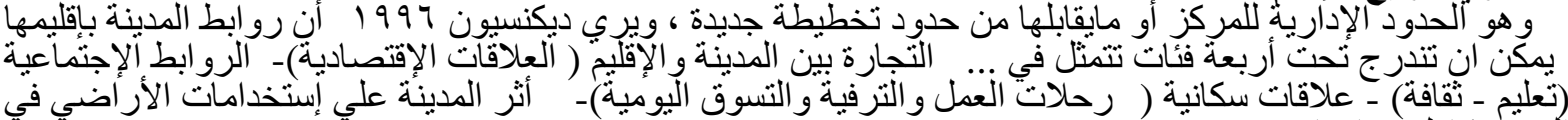

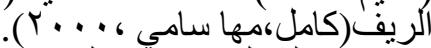

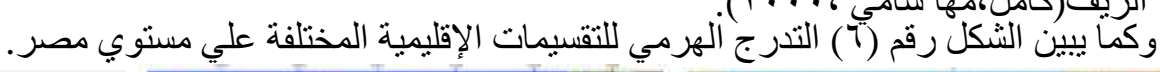

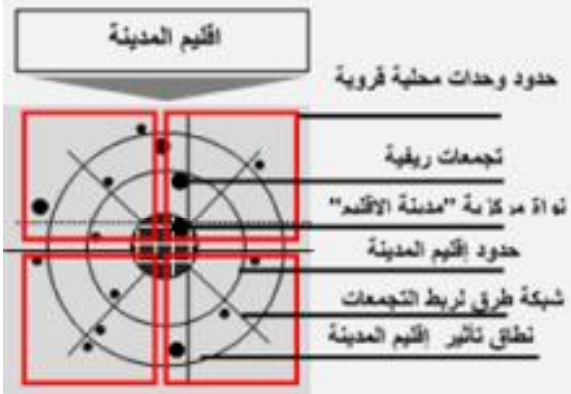

شكل رقم (0) مكونات إقليم المدينة

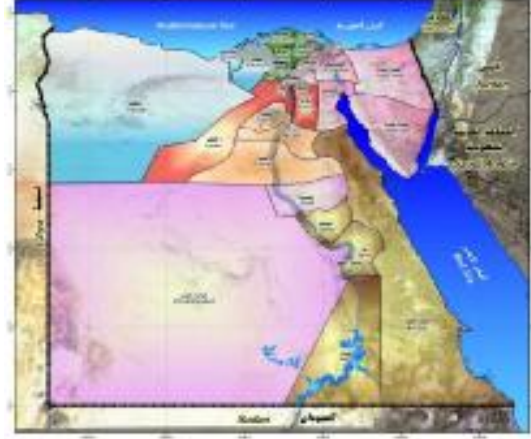

شكل رقم (؛ ) تقسيم مصر إلي محافظات

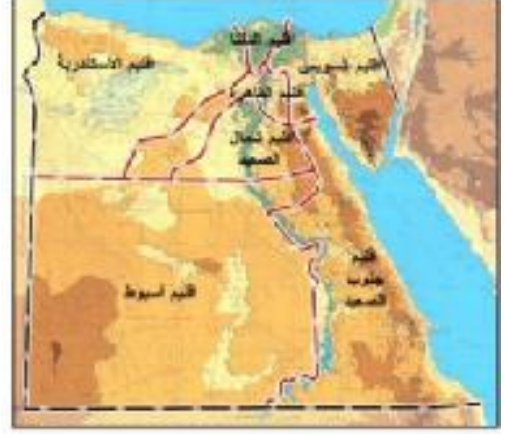

شكل رقم (r) تقسيم مصر إلي اقاليم إقصادية

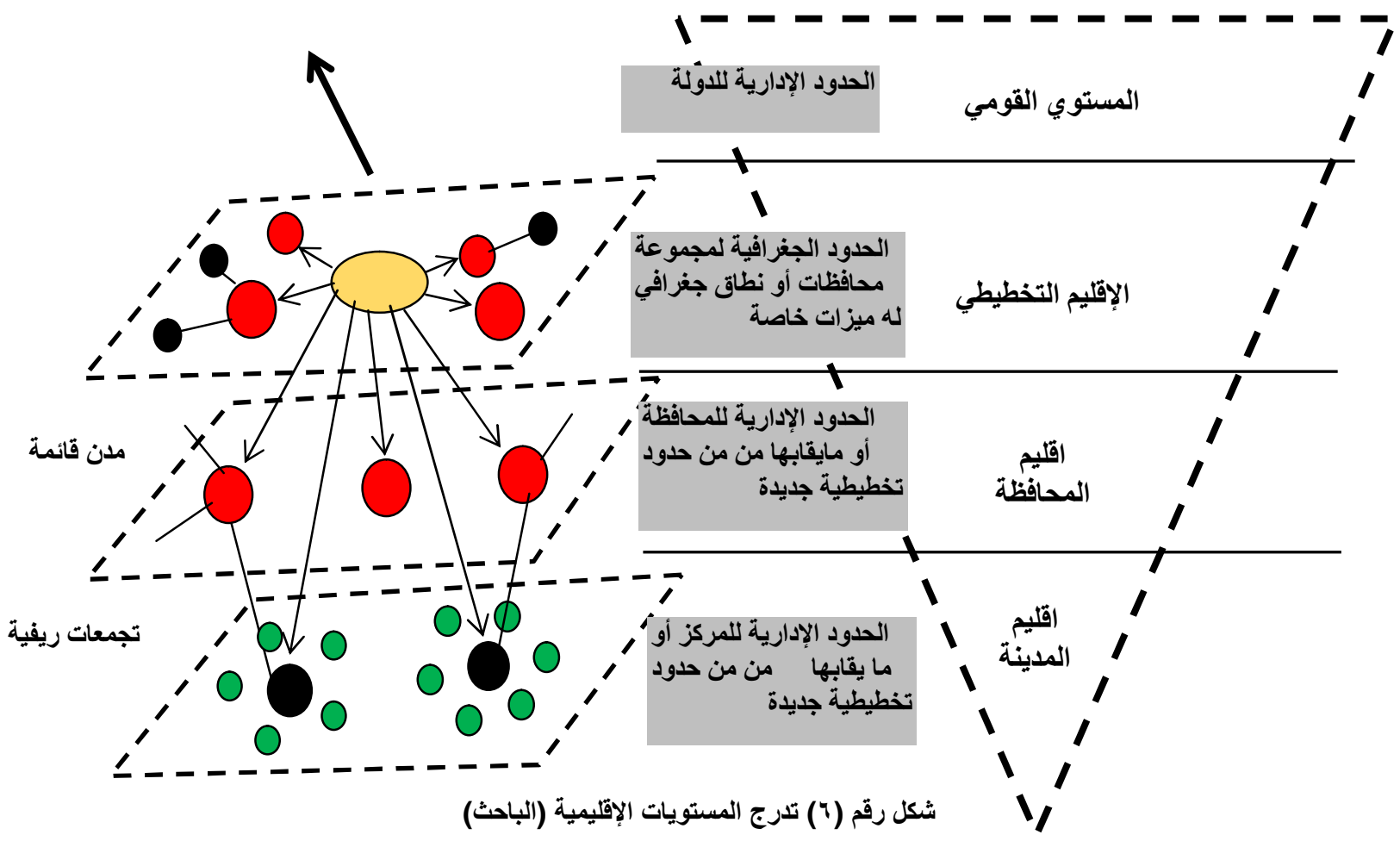

9. اعتبارات تحديد المستوي الإقليمي المناسب للتنمية الإقليمية

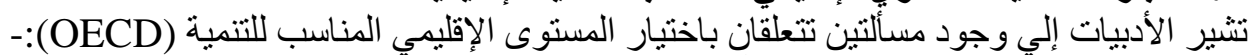
أ أ حساب القدرة التنافسية للإقليم وظيفياً.

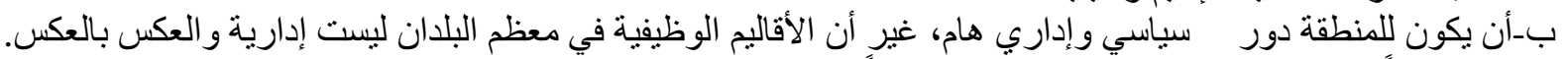

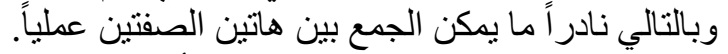

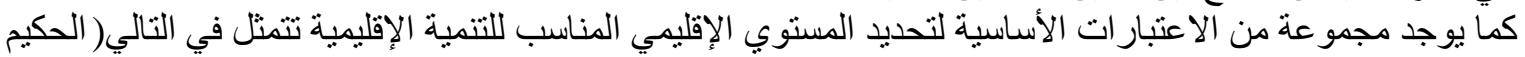

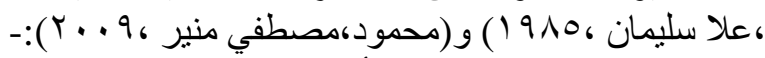
ـ القدرة علي دعم وجذب الأنشطة والأستثمار ات بقطاعات التنمية المختلفة و التي تجعل المستوي الإقليمي مناسبًا للتنمية الإقليمية. ـ ـ القدرة علي تحسين الميزة التنافسية والبنية التحتية وبيئة الاعمال لنمو القطاع الخاص وخلق فرص العمل.

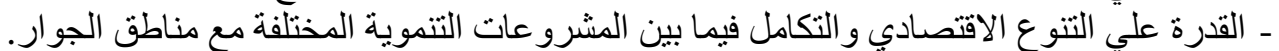

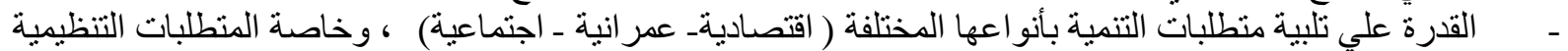
ـ القدرة علي إمتلاكث بنية تحتية تقافية جيدة تدعم المشاريع الفنبة و الترفيهية و الثقافية و السياحية . 
ـ والتنظيمية. ـ مدي تحقيق التو افق والتجانس للمستوي الإقليمي في السمات العمرانية ، الإقتصادية ، الإجتماعية ، البيئية ، الإدارية

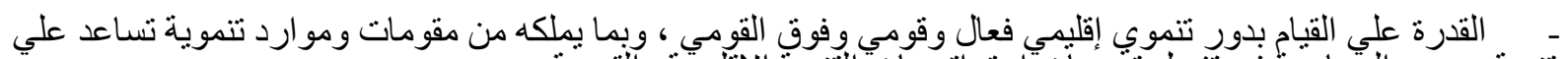

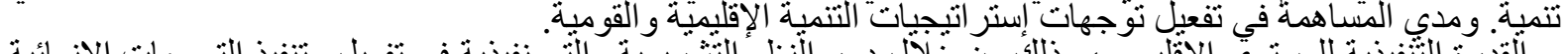

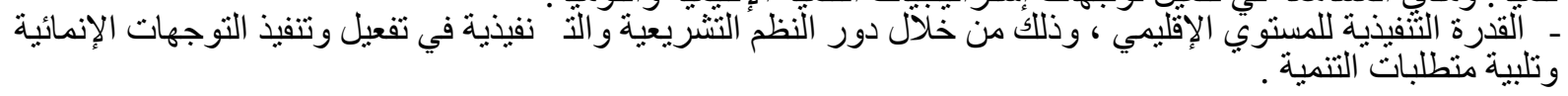

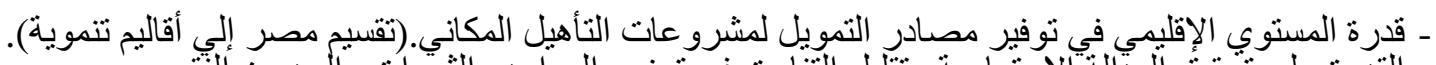

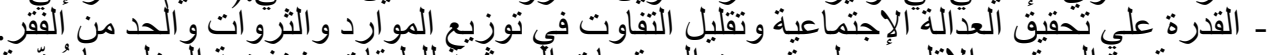

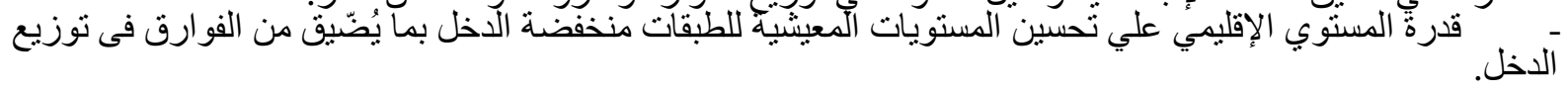

ـ ـ القدرة علي زيادة القدرة التوظيفية للإقتصاد المصرى بما يكفل معالجة مشكلة البطالة وتوفير فرص عمل .

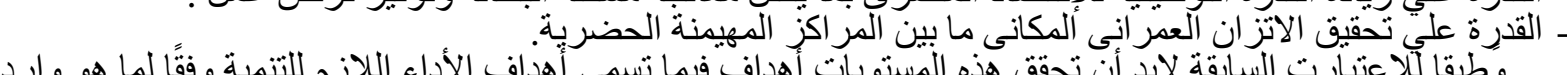

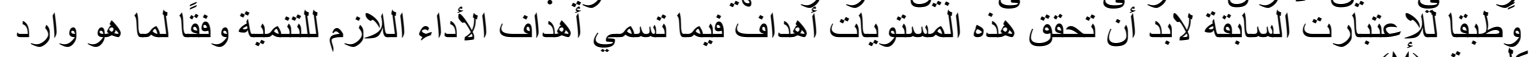

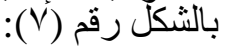

جدول رقم ("آ) تقييم المستويات الإقليمية في مصر لتحديد المستوي الإقليمي المناسب للتنمية الإقليمية

\begin{tabular}{|c|c|c|c|c|}
\hline المَلقينة & المحافظة & الإقلِصنّاد & 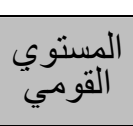 & الإعتبار ات الأساسية \\
\hline$*$ & + & $*$ & + & 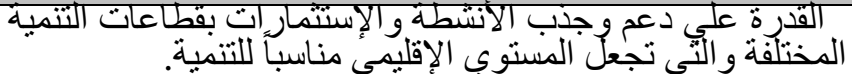 \\
\hline- & $*$ & $*$ & + & 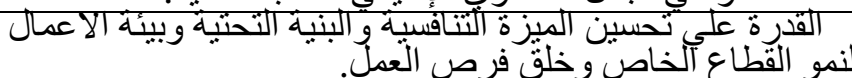 \\
\hline$*$ & $*$ & $*$ & $*$ & 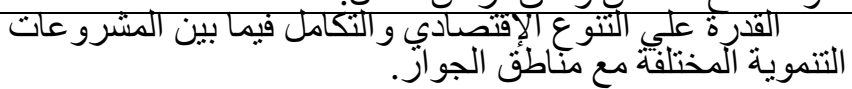 \\
\hline
\end{tabular}

$$
\text { أهداف الأداء التنموى }
$$

مسته بات التنمبة

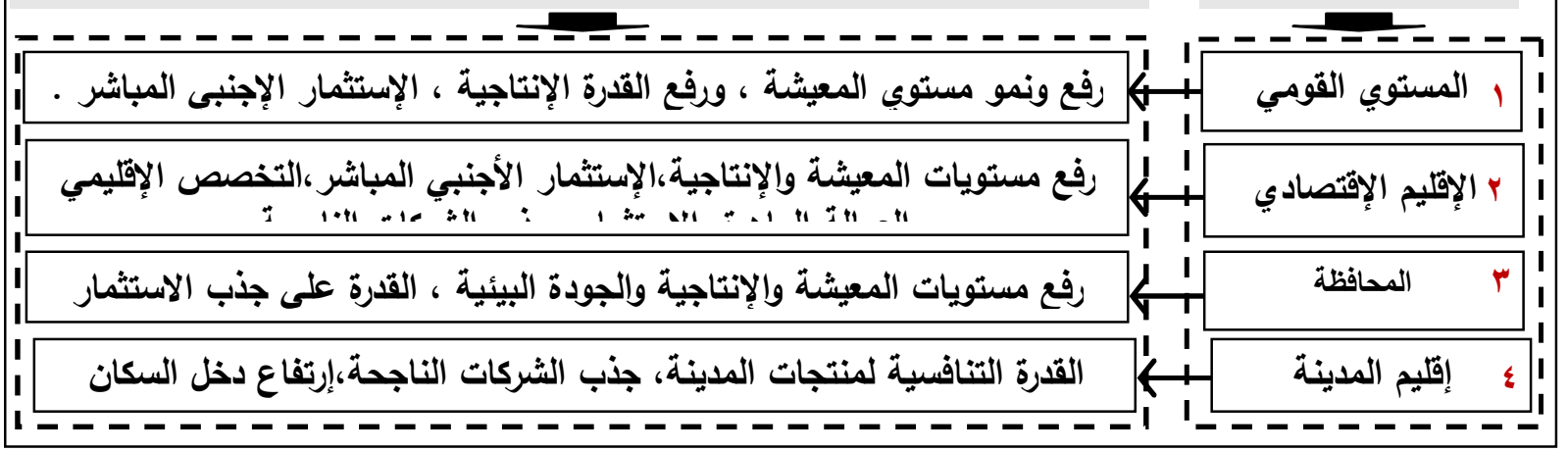

رفع مستوي المعيشة والدخل للسكان ، والقدرة علي جذب الإستثمارات و الثركات الناجحة هدف الاداء التنموي لناجح تنمية المحافظة المصرية.

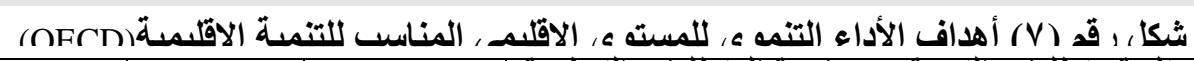

\begin{tabular}{|c|c|c|c|c|}
\hline+ & + & - & - & 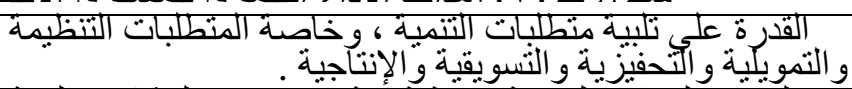 \\
\hline - & $*$ & $*$ & + & 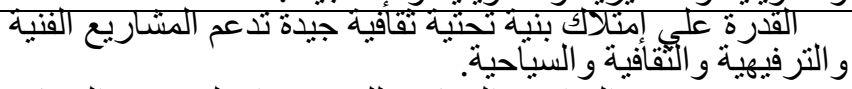 \\
\hline+ & $*$ & - & - & 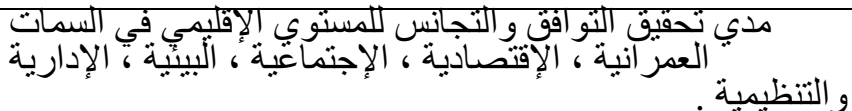 \\
\hline$*$ & + & $*$ & - & 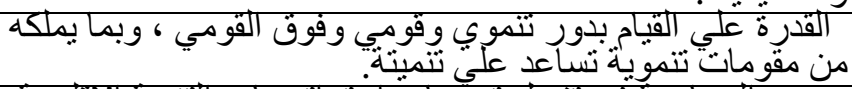 \\
\hline$*$ & + & $*$ & - & 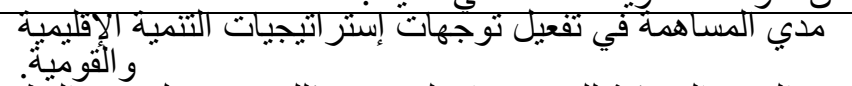 \\
\hline$*$ & + & - & * & 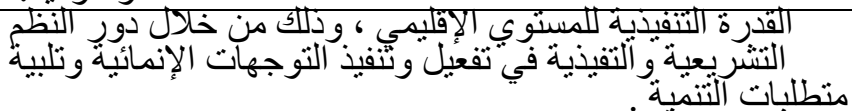 \\
\hline$*$ & + & $*$ & $*$ & 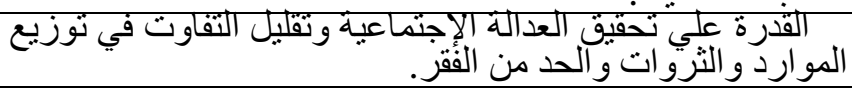 \\
\hline
\end{tabular}




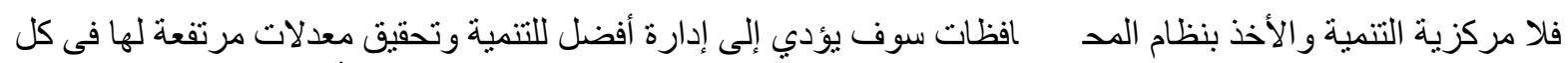

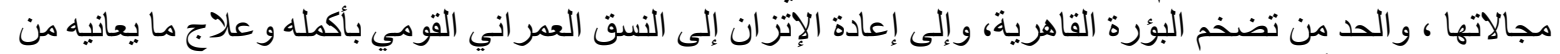

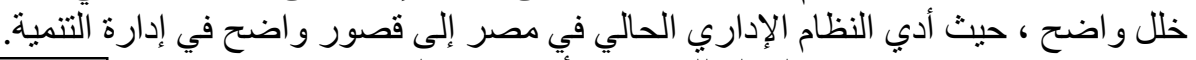

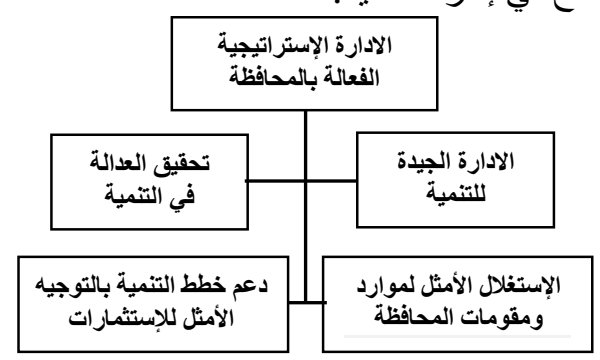

شكل رقم (9) اهداف الإدارة الإستراتيجية الفعالة

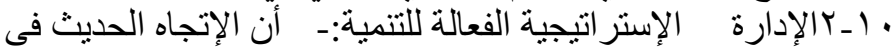

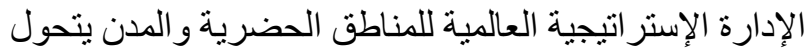

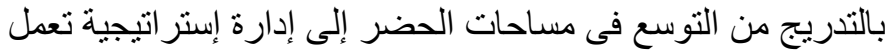

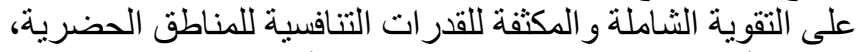

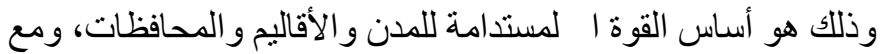
الأخذ بنظام المحافظات و لا مركزية الإدارة الإستر التيجية الفعالة بمكن الإني تحقيق الأهداف الآتية:-

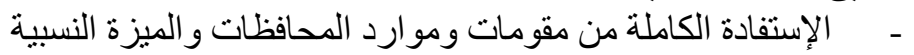

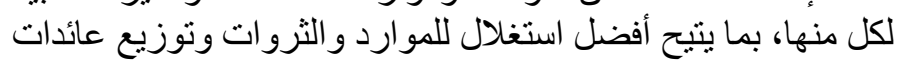

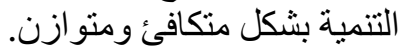

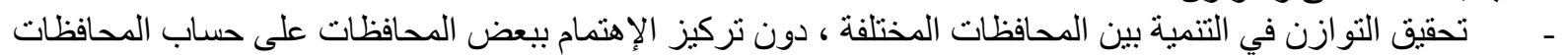

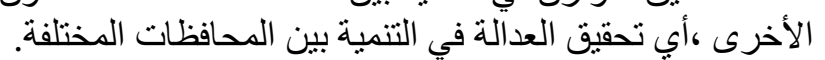

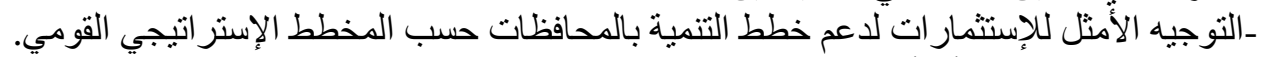

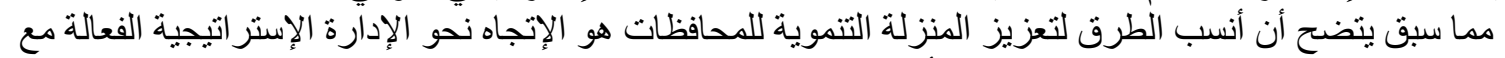

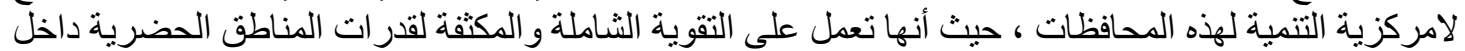

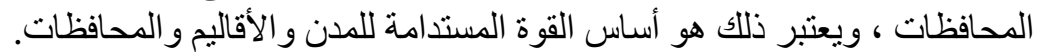
11

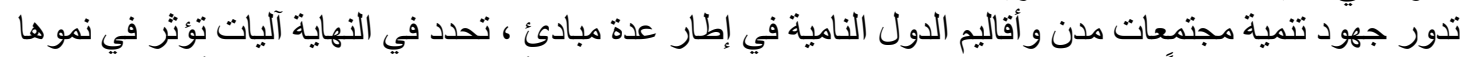

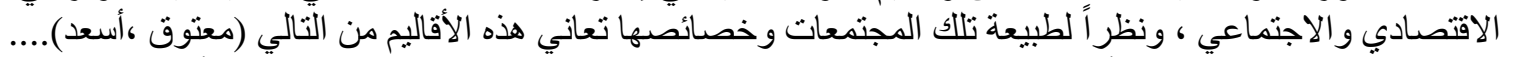

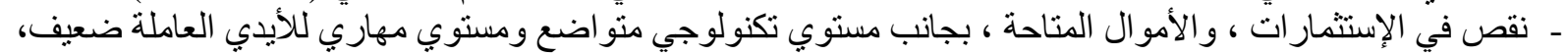

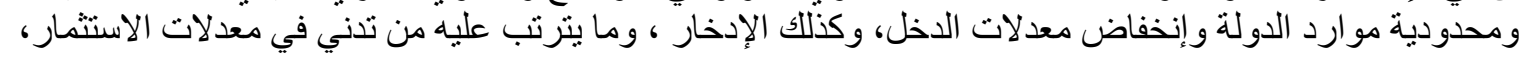

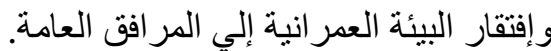

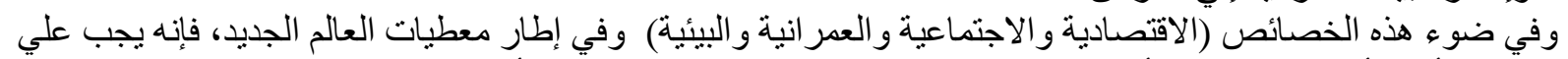

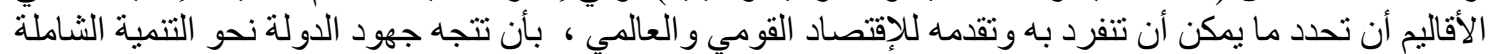

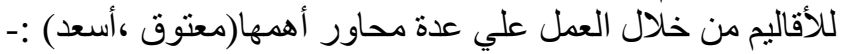

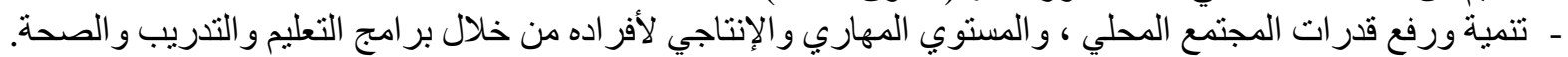

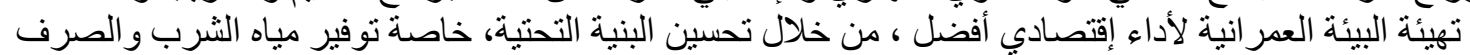

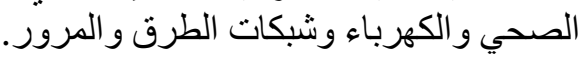

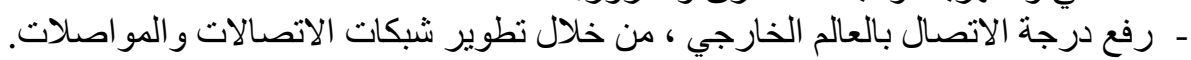

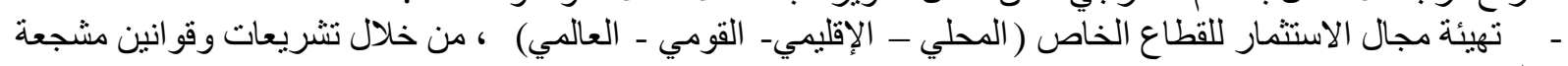

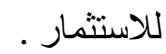

وضع مجمو عة من الموجهات الإستر اتيجية تساعد علي تشكيل اتجاهات التتمية علي المدي البعيد وتمثل نظر هـ شاملة

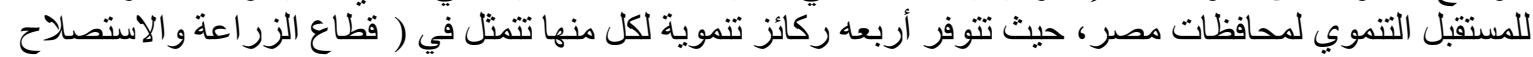

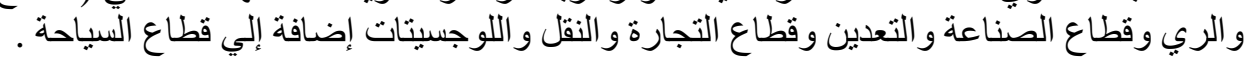

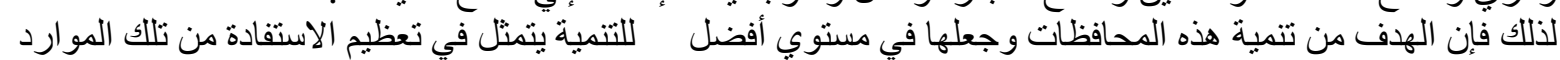

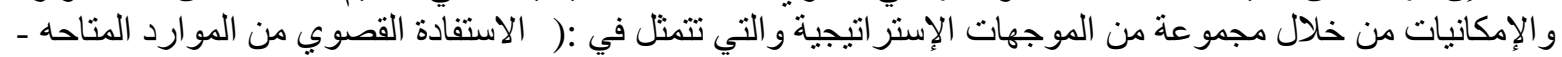

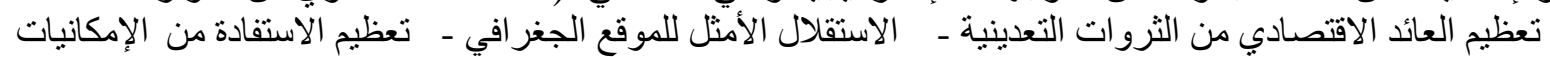

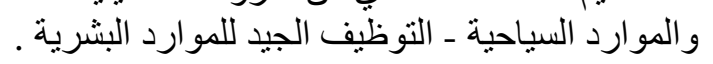

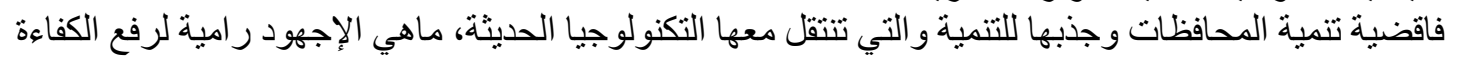

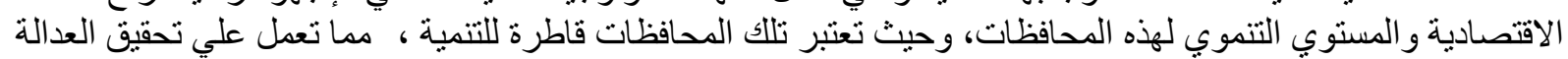

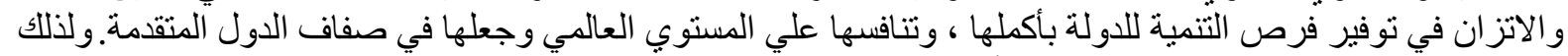

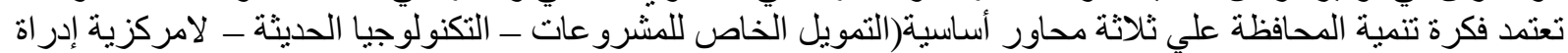
التنمية).

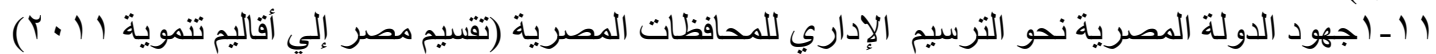

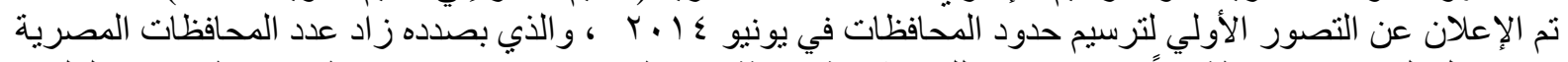

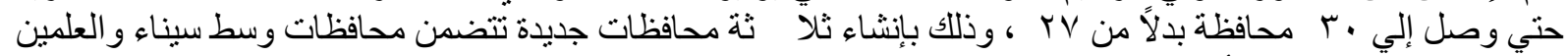

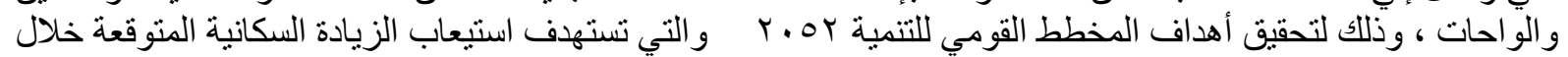

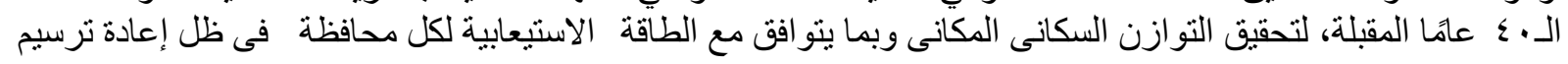


حدود المحافظات، و الذى يمكن من خلاله لكافة أجهزة و هيئات الدولة أن تعمل لتحقيق آمال وطموحات المو اطنين لتحقيق

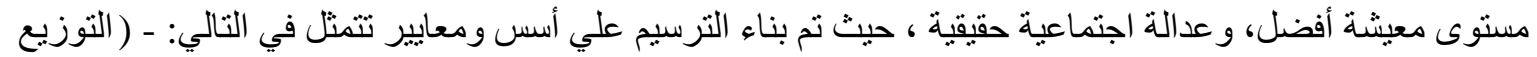

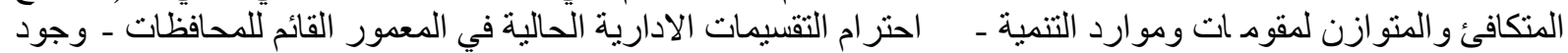

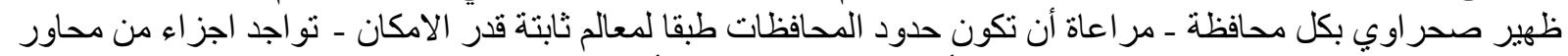

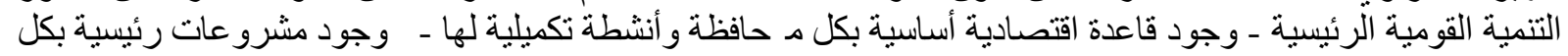

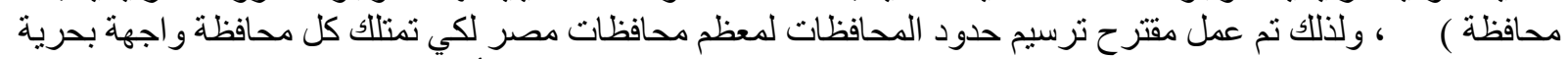

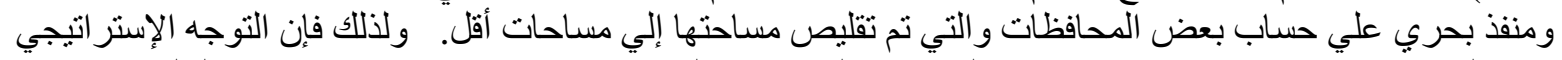

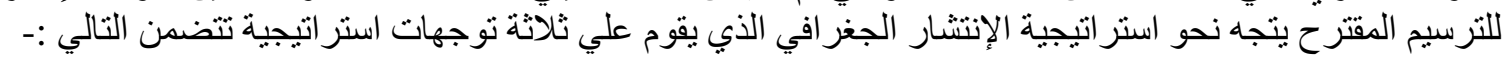

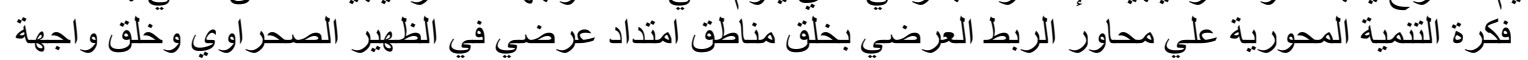
بحرية ومنفذ بحري لبعض البورية لمعظم المحافظات.

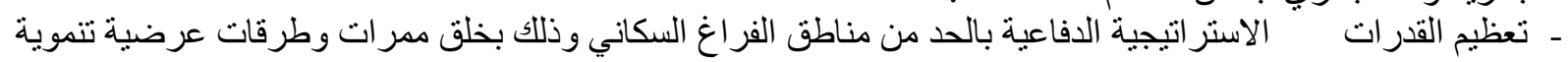

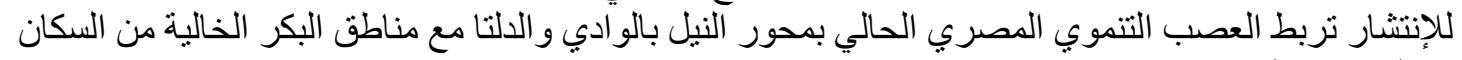

$$
\text { بالصحر اء الثرقية و الغربية. }
$$

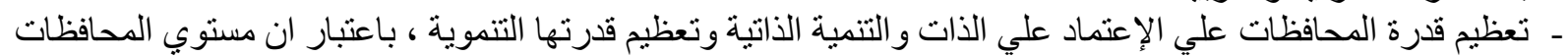

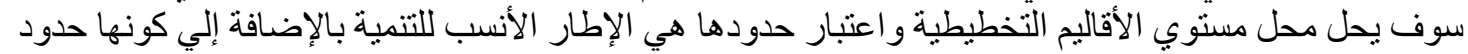

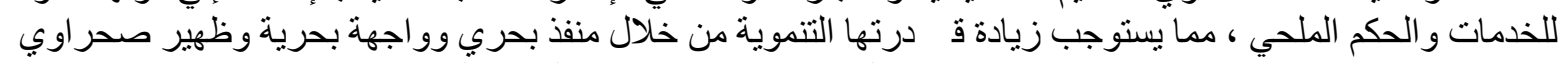
و وامتداد صحر اوي ضخم يوفر ظهير انتاجي من المشرو عات و الار اضي المستصلحة ومناطق استثمار سياحية جديدة

$$
\text { وتطوير الموانئ. }
$$

وكما تتمثل القوي الدافعة و المحفزات الإقتصادية لتتمية المحافظات المصرية في تو افر المق ومات واتو والإمكانيات البيئية

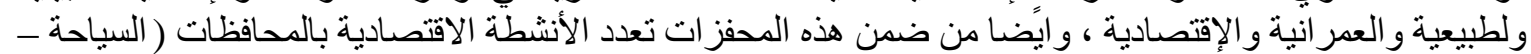

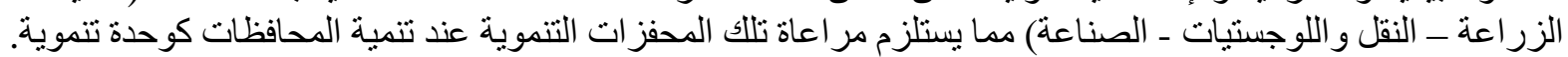

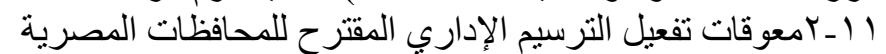

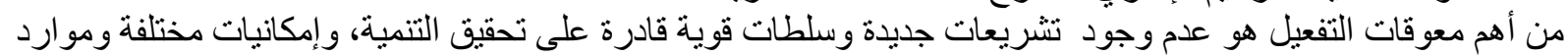

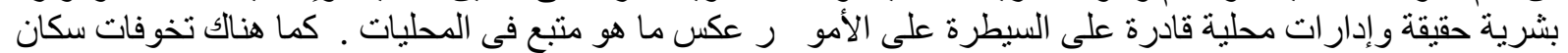

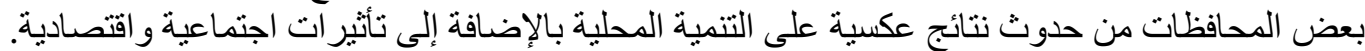

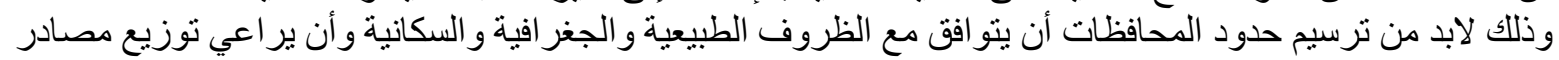

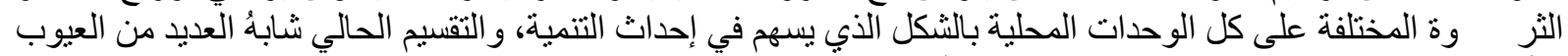

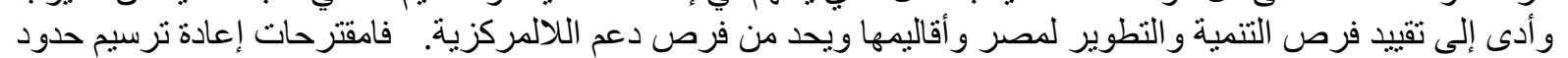

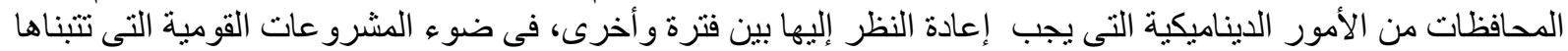

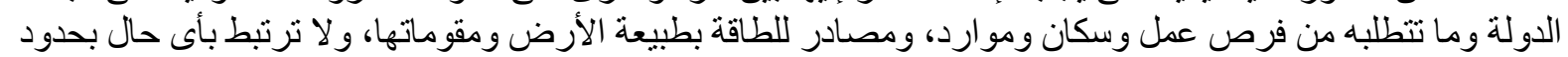

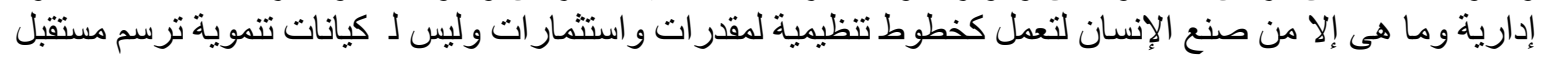

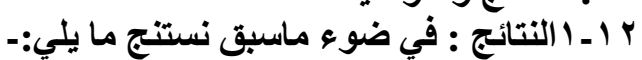

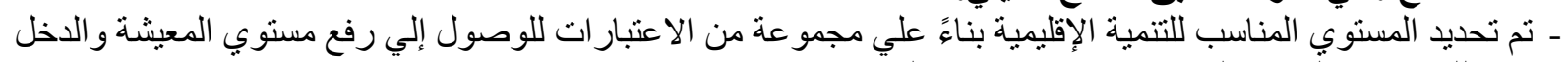

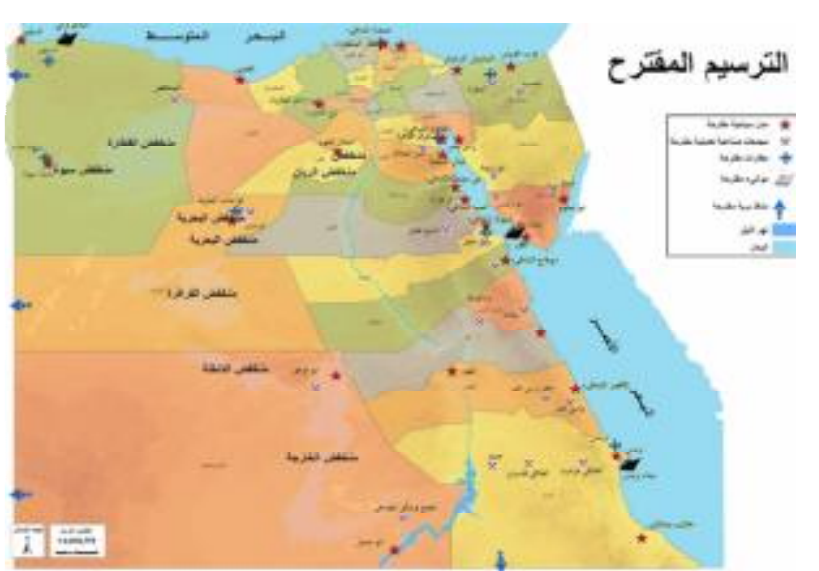

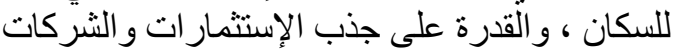

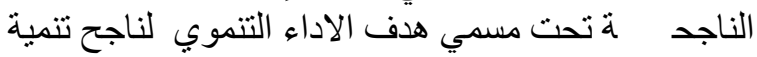
المحافظة المصرية. - - إيجاد وتحديد مستوي إقليمي مناسب للتنمية الإقليمية

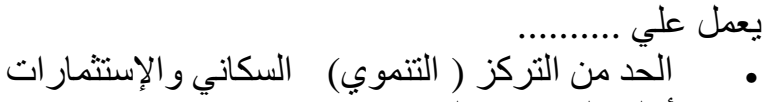
بالأقاليم الحضرية المتضخدة. • تحقيق إستدامة التتمية من خلال الإستغلال العذل المكاني للمو ارد و المقومات بكل محافظة.

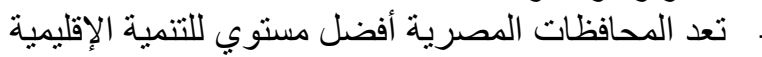

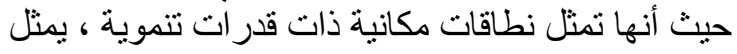

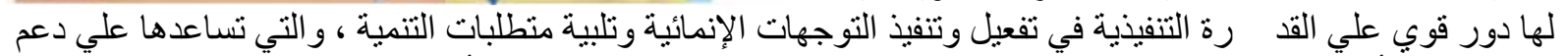

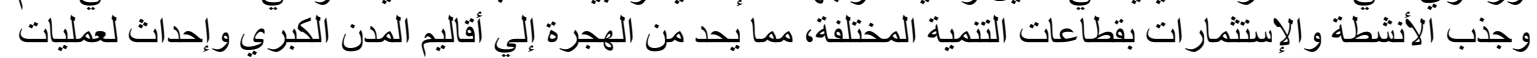
التنمية المتو ازنة علي مسنوي الأنطة الإنلة. 


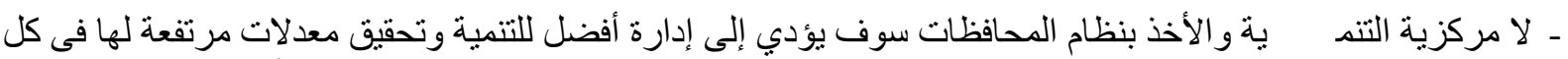

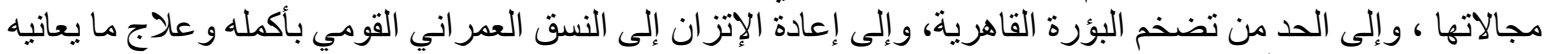

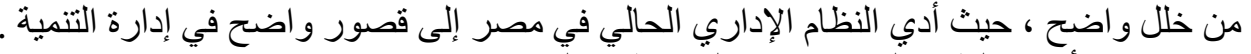

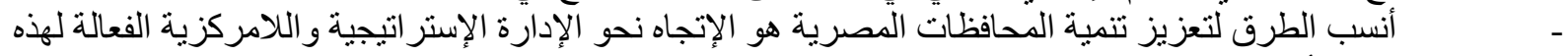

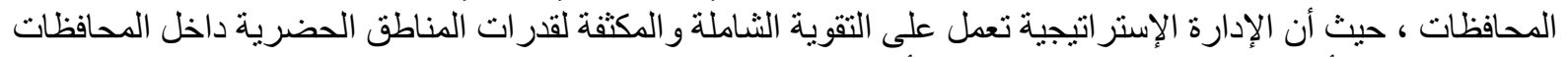

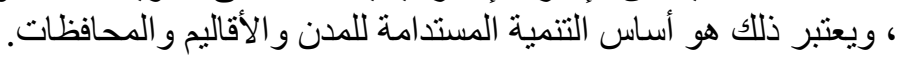

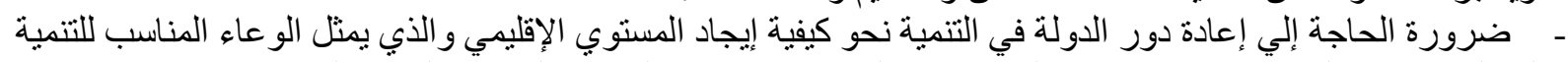

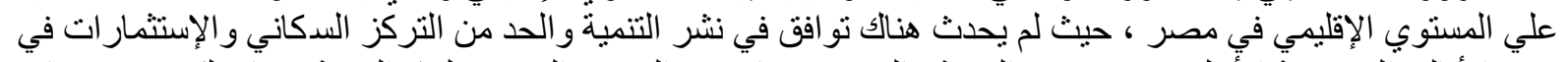

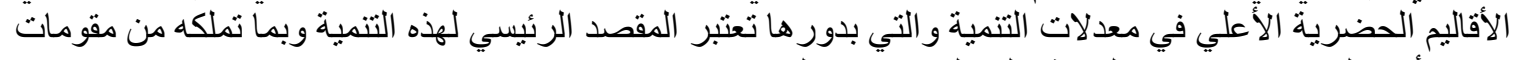

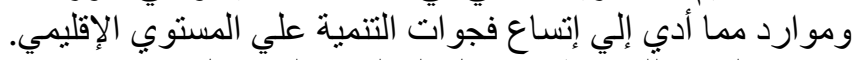

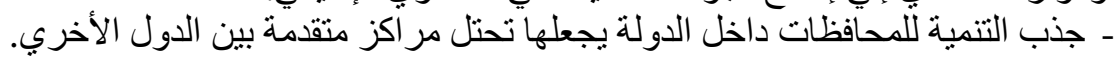

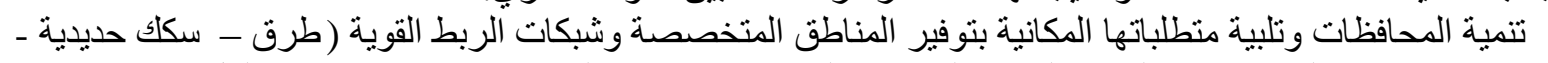

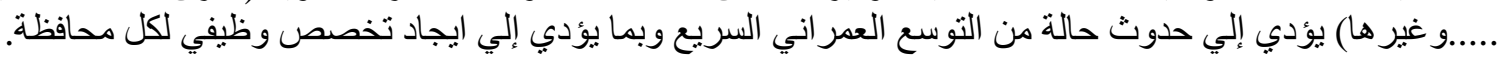

r r ا ـ ب التوصيات: خلص البحث إلي التوصيات بالتالي:-

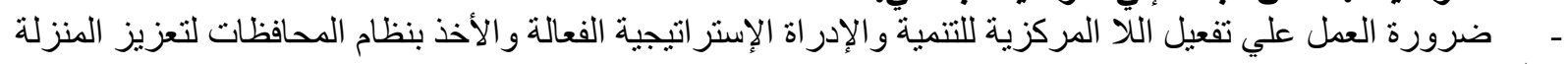
التنموية. - اعطاء دور للمحافظات في التنمية الإقليمية في تفعيل وتنفيذ التوجهات الإنمائية وتلبية متطلباتها ، والتي تساعدها علي

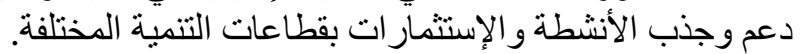

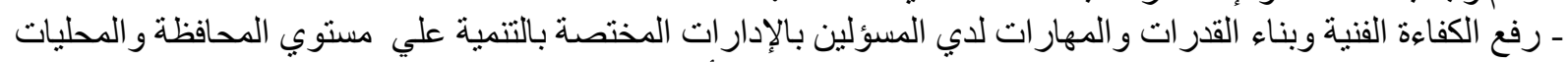

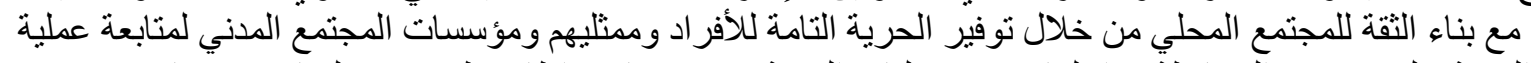

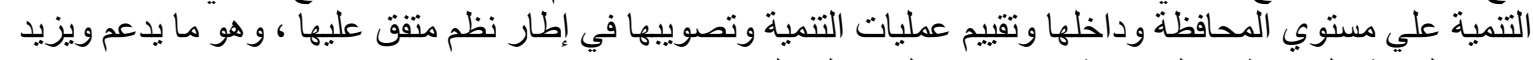

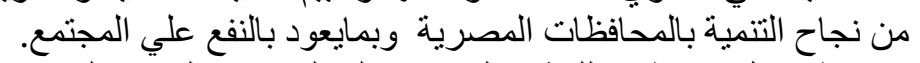

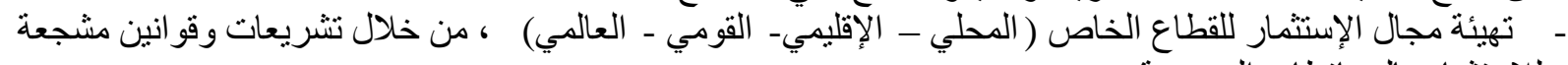

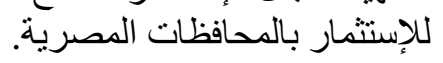

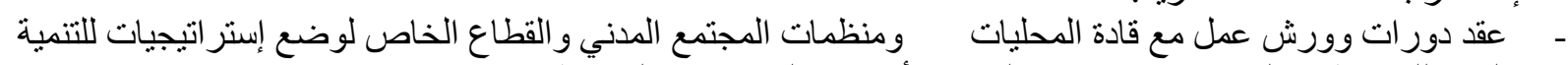

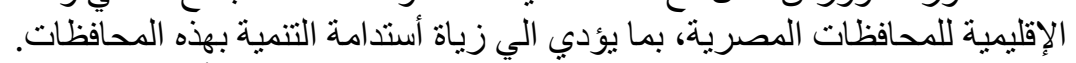

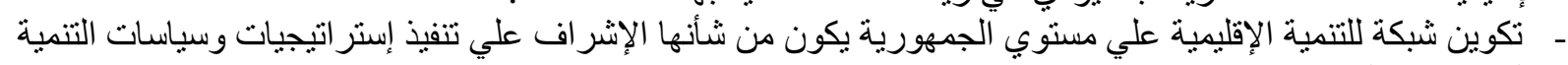
بالمحافظات المصرية.

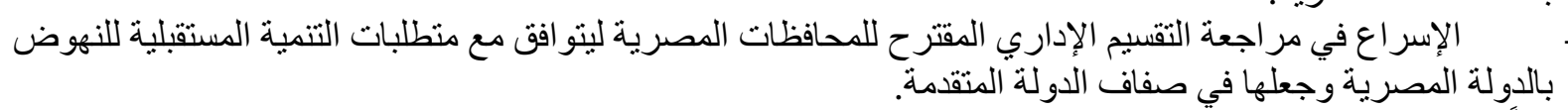

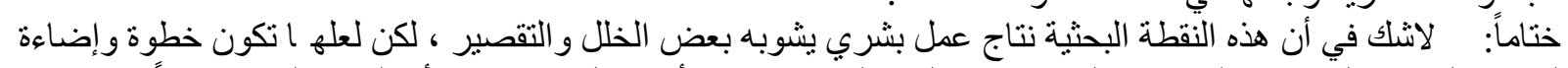

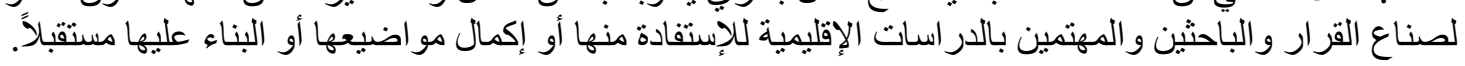

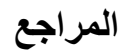 \\ ß}

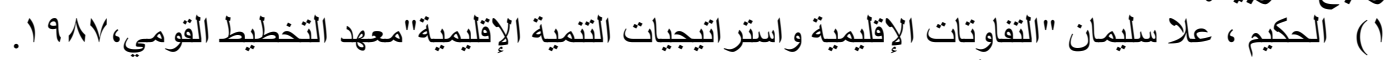

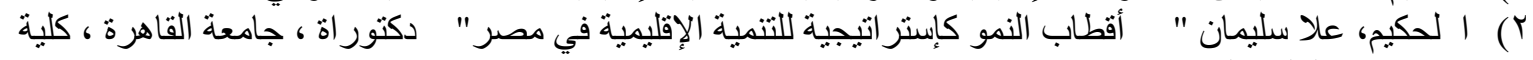

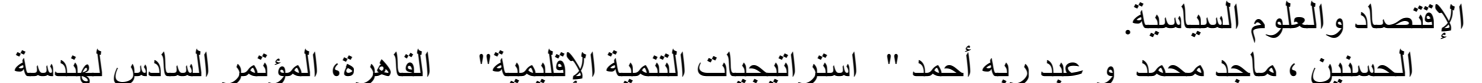

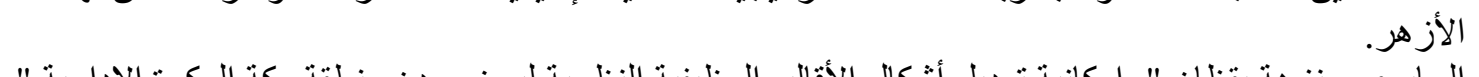

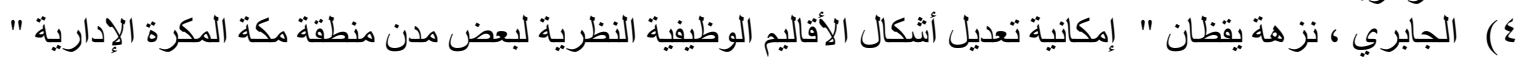

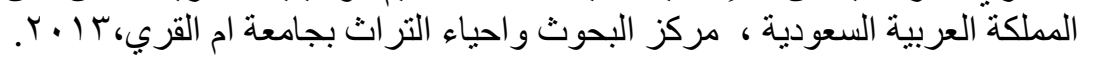

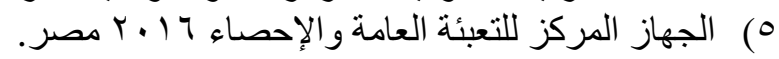

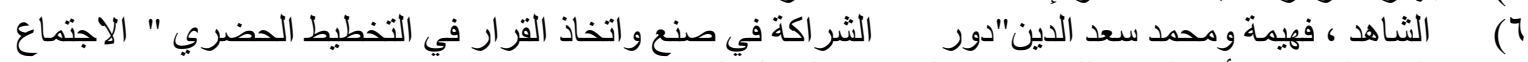

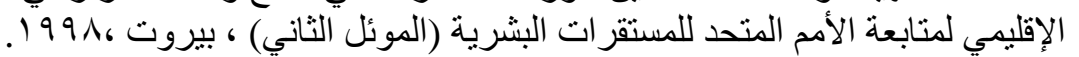

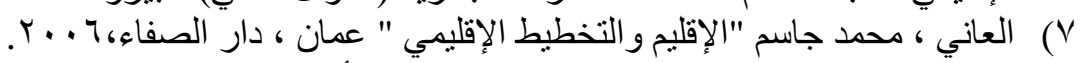

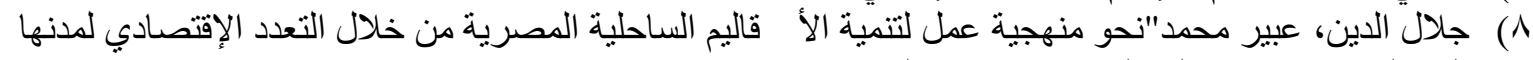

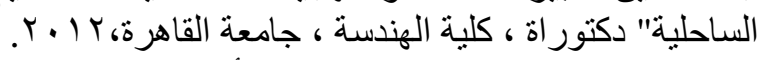

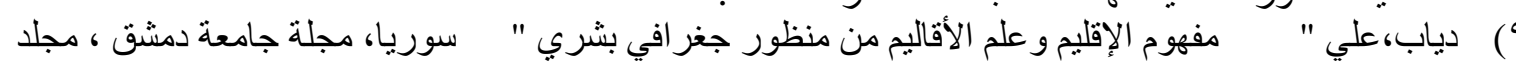
^ץ (العدد ألثاني). 


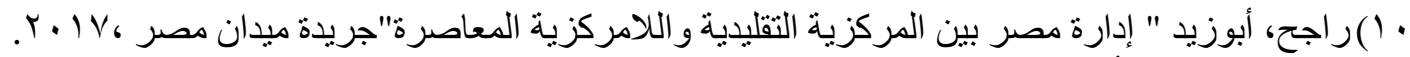

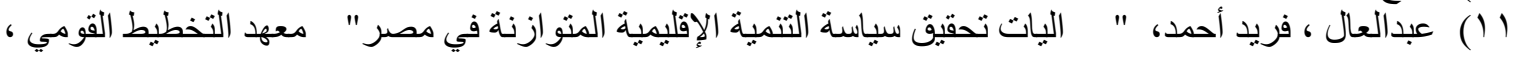

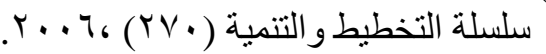

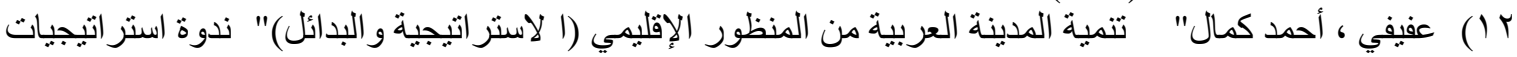

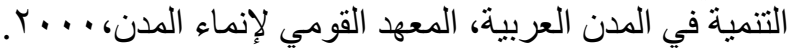

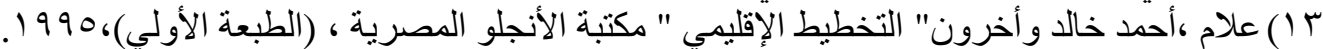

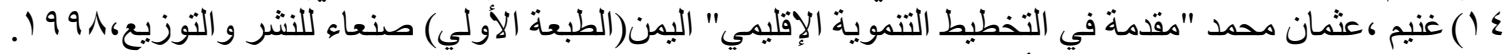

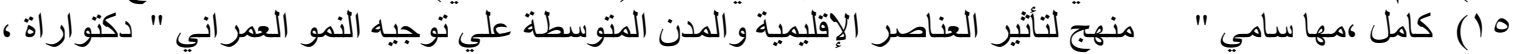

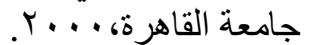

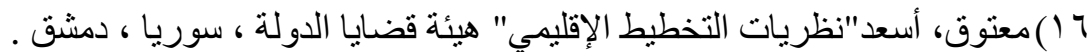

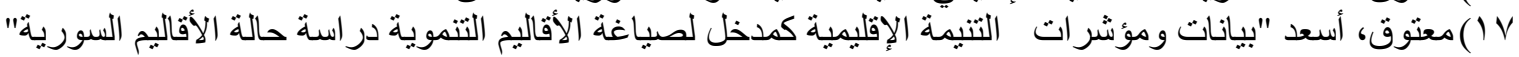

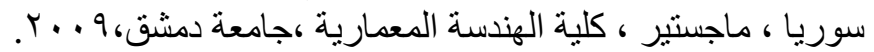

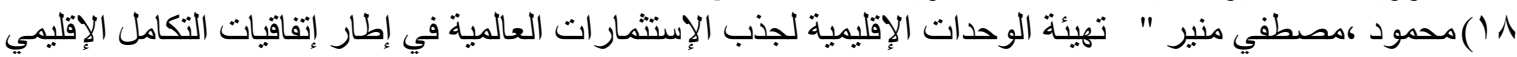

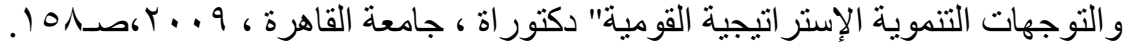

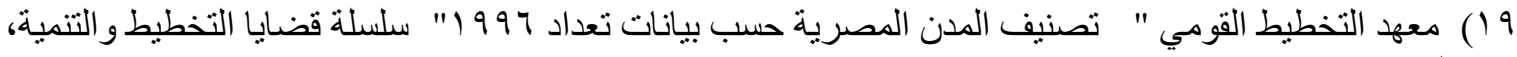

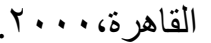

• †) وزارة الإسكان و المرفق و التتمية العمر انية ـ اله يئة العامة للتخطبط العمر اني - تقسم مصر إلي أقاليم تنموية ـ $r+11$

\section{ß English References:}

1. Geneva ‘The Global Competitiveness World Economic Forum. Report ,1999.

2. Consultative Guidelines For Sustainable Urban Development Cooperation - New Perspectives For Urban Development A Strategic - Approach2011.

3. Michael E Porter And Christian H M Ketels- Uk Competitiveness:Moving To The Next Stage- Harvard Business School2 2003.

4. United Kingdom's Adjusted Growth Strategy, 2015-Gturky

5. Http://Www.Oecd.Org,Oecdmetropolitan Database: Oecd Methodology For The Definition Of Metropolitan Regions. 